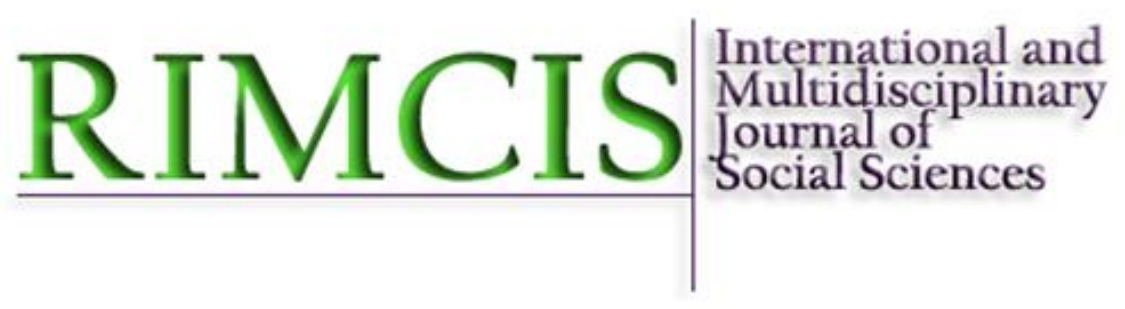

\title{
Volume 6, Number 1
}

\section{Hipatia Press \\ www.hipatiapress.com}

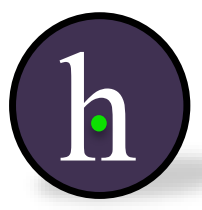

Evaluation of "Ready for First Certificate of English": Microstructural Approach - Ebrahim Khodadady, Atena Attaran...........................

Women Vulnerability in Informal Entertainment Sectors in Kathmandu:

A Human Rights Perspectives - Ghanashyam Niroula..

Sustaining Ghana's National Health Insurance Scheme Through

Preventive Healthcare Strategies and Legislation

- Samuel Adu-Gyamfi, Aminu Dramani.

Identifying the Relevance of Research Goals through Collecting Citizens' Voices on Social Media - Joan Cabré Olivé, Ramon Flecha García, Cristina Pulido, Vladia Ionescu, Teresa Sordé-Martí. 


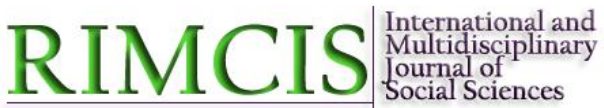

\section{Hipatia Press}

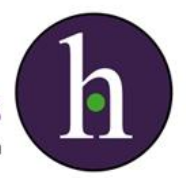

Instructions for authors, subscriptions and further details:

http://rimcis.hipatiapress.com

\section{Evaluation of "Ready for First Certificate of English" Reading Passages: Microstructural Approach}

Ebrahim Khodadady ${ }^{1}$, Atena Attaran ${ }^{1}$

1) Ferdowsi University of Mashhad, Iran

Date of publication: March $30^{\text {th }}, 2017$

Edition period: March 2017 - July 2017

To cite this article: Khodadady, E., \& Attaran, A. (2017). Evaluation of "Ready for Fist Certificate of English" Reading Passages: Microstructural Approach. International and Multidisciplinary Journal of Social Sciences, 6(1), 1-22. doi: 10.17583/rimcis.2017.2051

To link this article: http://doi.org/10.17583/rimcis.2017.2051

\section{PLEASE SCROLL DOWN FOR ARTICLE}

The terms and conditions of use are related to the Open Journal System and to Creative Commons Attribution License (CC-BY). 


\section{The Evaluation of "Ready for First Certificate of English" Reading Passages: Microstructural Approach}

Ebrahim Khodadady

Ferdowsi University of Mashhad
Atena Attaran

Ferdowsi University of Mashhad

\section{Abstract}

Despite much research done on language learning textbooks, there still exist several questions unanswered about what these textbooks' contents are about. This study is thus an attempt to investigate the 15 reading passages of "Ready for First Certificate of English" (FCE) in the light of schema theory. In doing so, the microstructural approach to schema theory was taken into the account which led to the classification of 8617 schema tokens into the three main categories of syntactic, semantic, and parasyntactic domains. Running the chi-square test revealed that the domains differ significantly from each other regarding both their types $\left(\mathrm{X}^{2}=2869.9, p<0.05\right)$ and tokens $\left(X^{2}=1704, p<0.05\right)$ which lent support to their psychological reality. In addition, the descriptive analysis of the schemata demonstrated that reading passages are heavily outweighed by semantic types (80.7\%), whereas syntactic and parasyntactic types formed only about $6 \%$ and $12.4 \%$ of the textbook, respectively. The pedagogical implication of the study is discussed and further suggestions are put forward.

Keywords: schema theory, microstructural approach, semantic domain, syntactic domain, parasyntactic domain 


\section{La Evaluación de los Fragmentos de Lectura del "Ready for First Certificate of English": Una Perspectiva Microestructural}

Ebrahim Khodadady

Ferdowsi University of Mashhad
Atena Attaran

Ferdowsi University of Mashhad

\section{Resumen}

A pesar que los libros de texto para el aprendizaje de idiomas se ha investigado mucho, aún hay varias cuestiones sin responder acerca de la temática de su contenido. Este estudio es, pues, un intento de investigar los quince fragmentos de lectura del "Ready for First Certificate of English" (FCE) a la luz de la teoría del esquema. De esta manera, se tuvo en cuenta una perspectiva microestructural de la teoría del esquema lo que condujo a la clasificación de 8617 muestras de esquemas en las tres principales categorías de los dominios sintáctico, semántico y parasintáctico. La prueba del chi-cuadrado mostró que los dominios difieren significativamente los unos de los otros teniendo en cuenta tanto su tipo $(\mathrm{X} 2=2869.9, \mathrm{p}<0.05)$ como su muestra $(\mathrm{X} 2=1704, \mathrm{p}<0.05)$ lo que condujo a reforzar su realidad psicológica. Así mismo, el análisis descriptivo de los esquemas demostró que los fragmentos de lectura están fuertemente sobreponderados por los tipos semánticos $(80.7 \%)$, mientras que que los tipos sintáctico y parasintáctico conforman sólo alrededor del $6 \%$ y el $12.4 \%$ respectivamente de los libros de texto. Se debaten las implicaciones pedagógicas del estudio y se avanzan sugerencias para futuras investigaciones.

Palabras clave: teoría del esquema, perspectiva microestructural, dominio semántico, dominio sintáctico, dominio parasintáctico 


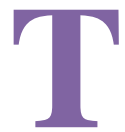

he saliency of textbooks in English language teaching (ELT henceforth) classes cannot be ignored due to their importance in providing language input and practices for language learners (Richards, 2001). Textbooks as the "visible part of any ELT program" (Sheldon, 1988) are the means of consistency in the language learning process and can give learners a sense of cohesion and belonging to a system (Toms, 2004). In fact, textbooks can provide the teachers with good models to map out their own materials (Nunan, 1987) and also guide students and balance the contents they need to learn. The content of a textbook not only does transfer knowledge and information, but also develop certain attitudes in the mind of the learners. Consequently, evaluating English as a Foreign Language (EFL) or English as a Second Language (ESL) textbooks in any educational program can be of utmost importance.

In fact, not only evaluating teaching materials plays a pivotal role in any educational system, it also helps administrators, teachers, and supervisors to "make judgments about the effects of the textbooks on the people using them" (Tomlinson, Dat, Masuhara \& Rubdy, 2001, p. 85). This evaluation can be done in three different stages, namely pre-use, in the process, and retrospective stages. As the names suggest the pre-use stages embraces evaluation at the time when materials are seen as work plans or constructs; the next step involves judging materials in process during which it is used; and the final stage occurs when the outcomes from materials use are considered (Breen, 1989).

There have been numerous studies which aim at defining and evaluating the characteristics of textbooks (e.g. Chastain, 1971; Gharbavi \& Mousavi, 2012; Hutchinson \& Waters, 1987; Rashidi \& Ghaedsharafi, 2015; Tucker, 1975; Ur, 1996; Van Leeuwen, 1996). While most of these studies are mainly based on checklists, questionnaire, and corpus analysis, some address issues like gender, culture, and grammatical points. Although they provide useful insights toward the materials evaluated, they mostly suffer from the fact that they are too general and thus either fail to accommodate some fundamental details or pay too much attention to one aspect of language like modals (e.g. Khojasteh \& Reinders, 2013).

Nevertheless, to provide a meticulous evaluation of a textbook, there is, in fact, a need for considering all aspects of its language including semantic, 
syntactic, and also parasyntactic ones and then examining their values and socio-cultural aspects. The reason behind this is that comprehension of texts involves the rapid integration of various types of semantic and syntactic knowledge (Altmann, Garnham \& Dennis, 1992; Tanenhaus, SpiveyKnowlton, Eberhard \& Sedivy, 1995). Moreover, there is a balance in how much attention we are supposed to pay to general and specific aspects of a book. In this regard, the microstructural approach toward schema theory analyzes each and every word of a text and assigns them to semantic, syntactic, and parasyntactic domains (Khodadady, 1997, 2004, 2013) to delve into the underlying layers of words objectively and avoid any ambiguous, general, and inaccurate judgments about texts.

Although the microstructural approach to schema theory (MICAST) has been applied to reading comprehension ability and language testing (Khodadady, 1997), it is highly likely the time to employ it in analyzing and evaluating textbooks. "Ready for FCE" (Norris, 2008) is a book which is taught in many language institutes in Iran to FCE candidates as well as learners at upper intermediate or advanced levels. Therefore, due to the importance of this book in the educational system of language institutes, this study aims at evaluating its reading passages in the light of the MICAST.

\section{Review of Literature}

\section{Schema Theory}

Schema theory was an attempt to explain learning in the early 1900 s (e.g. Bartlett, 1932; Head, 1920; Piaget, 1926) which was inspired mainly by cognitive psychology (e.g., Rumelhart, 1975) and the early Gestalt psychology of the 1920s. It was also a great help to the studies done in the realm of artificial intelligence. Barlett (1932) considered schema as "memory structures abstracted from idiosyncratic experiences" which play a significant role in the processes of narrative comprehension and recall (Hakemulder, 2006). Schema theory thus shed light on the way of people go through their everyday experiences by providing "explanation for facts from human cognitive adaptability to the use of definite reference in specific circumstances" (Stockwell, 2006, p. 12). Semino (1997) categorized 
schemata into three types of 'world schemas,' 'text schemas,' and 'language schemas'. While the first represents conceptual contents like the restaurant script, the second deals with our expectation of the sequence and organization of content scripts, and finally, the third fulfills our expectation of the appropriate linguistic and pragmatic features in which the world is articulated.

The three categories described above seem to be basically macrostructural in scope. It characterizes schema as scripted or rhetorical knowledge. In this regard, knowing schema means knowing the structural patterns of various texts such as narratives and expository ones (e.g., McNeil, 1987; Poplin, 1988). The MICAST, however, considers each single and phrasal word as a schema (Khodadady, 1997, 2004, 2013; Khodadady \& Herriman, 2000). In this view, and schemata are characterized as the words upon which the authentic texts are built. They fall within the three linguistic domains of semantic, syntactic and parasyntactic schemata (Khodadady, 2001, 2008a; Khodadady \& Hesarzadeh, 2014). Consequently, to test comprehension ability it is essential to adopt a microstructural rather than macrostructural approach.

In the MICAST, each linguistic domain is hierarchically formed by its genera, which in turn consists of species and types. The semantic domain which is open in type comprises four genera, i.e., adjectives, adverbs, nouns, and verbs. The genus of verbs, in turn, contains species such as complex, derivational, and phrasal verbs. And finally, each species consist of an open set of types such as underlie and undertake. The syntactic domain which is closed in type includes auxiliaries, conjunctions, determiners, prepositions and pronouns and the last domain comprises schemata such as numerals, abbreviations, names and para adverbs.

Based on the MICAST, Khodadady (2008b) examined 22 newspaper and magazine articles dealing with political issues. Categorizing the texts schemata into the three main domains and running the chi-square test on the data revealed that semantic, syntactic, and parasyntactic schemata differed both in type and subcategorization. Moreover, semantic schemata had the greatest share of the texts $(77 \%)$ and parasyntactic and syntactic schemata accounted only for $17 \%$ and $6 \%$ of the text, respectively, which supports the priority of teaching meaning in English classroom. 
In another study, Khodadady and Kosravani (2014) aimed at delving certain texts into the two ideologically opposed news media, the BBC and Press TV, to cover the Syrian crisis. In doing so, they adopted the MICAST to analyse 26 news articles broadcasted by these two news media. The results of their study showed that both agencies benefit from semantic schemata more than the other two types, however, they differ significantly in number. More importantly, this approach has been used as a means of critical discourse analysis which could objectively show that putting certain schemata together reveal the ideological standpoints of text producers regarding a specific subject or ideology.

The empirical studies of employing the MICAST move beyond textual and discourse analysis. Khodadady, Pishghadam, and Fakhar (2010), for example, studied the relationship among reading comprehension ability, grammar and vocabulary knowledge on certain units of three textbooks taught at an intermediate level of language proficiency. The benefits of employing schema-based comprehension test are that they enjoy construct validity and they measure the academic achievement of learners objectively. In another study, Khodadady, Shirmohammadi and Talebi (2011) analyzed brainstorming and investigated its effect on critical thinking and speaking skills. The findings suggested that semantic schemata such as nouns are many in type but few in their frequency (token), whereas the syntactic schemata such as pronouns are few in type but many in frequency. Parasyntactic schemata such as names may be many in both type and frequency but always play a syntactic role in language comprehension and production.

The findings in each realm provide not only comprehensive but also an objective understanding of the subject area. In this regard, reading comprehension texts as an integral component of any textbook are also needed to be looked at through the lens of a microstructural approach.

\section{Cambridge First Certificate in English}

Cambridge First Certificate in English (FCE) is the second oldest exam offered by Cambridge English Language Assessment system (Zeronis \& 
Geranpayeh, 2015) which corresponds to CEFR level B2 - Independent User. It is a qualification at upper-intermediate level.

Cambridge English exams consider that communicative language ability as divisible to different sub-skills and abilities (Geranpayeh, 2007) and consequently, "language develop differently in each individual and can be measured as separate aspects of language ability" (Docherty, 2015). According to this basic notion, FCE exam consists of five sections: Reading, Writing, Use of English, Listening, and Speaking. However, since 2015 the Reading and the Use of English papers merged into one paper and tasks were shortened. In the revised version the reading topic revolved more around the vocational and educational issues to prepare students both for working in an English-speaking environment and furthering education (Howden \& Mehta, 2015; Zeronis \& Geranpayeh, 2015).

This exam is among one of the most popular Cambridge exams and a large number of students participate in it annually since 1) they can improve their job prospects; 2) continue their study; 3) it is recommended by their teachers; 4) it is a prestigious exam; 5) it is good for their personal development; 6) it is recognized as a school-leaving qualification (Howden \& Metha, 2015).

Therefore, due to the importance of the exam different aspects of the exam are addressed by scholars. Purpura (1997), for example, tried to analyze the cognitive and metacognitive strategies EFL/ESL learners apply on FCE tests. The findings proposed that learners at the intermediate level of proficiency benefit from the ability to decode grammar and vocabulary, rather than do a top-down or interactive reading at higher levels of processing as suggested by Taylor, Harris and Pearson (1988). Daftarifard and Birjandi (2015) also scrutinized lower intermediate EFL learners' performance on the reading section of the FCE exam. Their study showed that low proficient language learners could not properly make use of cognitive strategies. Moreover, good readers' uses of Planning and Monitoring metacognitive strategies were significantly better than those of poor readers.

Tsagari (2011) also explored the influence of First Certificate in English (FCE) exam on teachers' classroom practices. It was found that teachers highlighted the topics and skills expected to be tested in the exam due to the 
accountable pressure for the results of the students. In fact, it was shown that classroom practices mostly deals with exam oriented materials and intense preparation activities.

So far the studies mainly dealt with the exam itself rather than the available exam resources and books in the market. In doing so, Roohani and Tanbakooei (2012) compared First Certificate and Passages 1 textbooks by adopting critical discourse analysis framework. They particularly focused on social relations, subject positions, and contents in the conversation as well as vocabulary and grammar parts. Their results revealed that both textbooks encouraged equal social relations between men and women with equal social status and power. However, Passages 1 paid more attention to friends' social relation, while First Certificate gave priority to $T V$ reporting. Regarding the content, Passages 1 mostly focused on uncontroversial issues, whereas First Certificate concentrated on controversial and market-oriented topics more than Passages 1. After all, both of these textbooks had the tendency to picture the cultural and ideological aspects of Western countries to language learners.

As can be noticed, the above studies provide no objective insight into what the FCE preparation exam books contain and there is no accurate picture of what such books include. Studies of FCE mostly have been carried out on the exam and no study has addressed the objective analysis of book contents. As a result, the purpose of this study is to examine closely and objectively the reading passages of "Ready for FCE" (Norris, 2008) by employing the MICAST to help the FCE candidates achieve their expectations in the exam.

\section{Methodology}

\section{Material}

This study analyzes fifteen reading passages of "Ready for FCE" (Norris, 2008) which aims at preparing English language learners for the FCE test. In fact, this book is situated at level B2 of the Common European Framework which is named Vantage. In this level learners are expected to express themselves on a range of topics and achieve their goals. The first criterion in 
selecting this book was its being published internationally by one of the leading publishers, Macmillan. Additionally, the passages are longer than books in the lower levels and thus provide a better chance for the analysis of its writer's word choice.

\section{Procedure}

The contents of the reading passages from FCE was first typed and broken into their single/phrasal words representing specific concepts as schemata. Following Khodadady and Lagziyan (2013), parsed schemata were assigned to semantic, syntactic and parasyntatic domains. Each domain schema was then assigned to its genera. The genus schemata were, in turn, subcategorized into their constituting species. Upon specifying the 122 species of the 16 genera, the types and tokens of species were then counted. Moreover, to increase the reliability of the results, the codes assigned to schemata were double-checked after passing about one month from the first analysis.

\section{Data Analysis}

The readability level of each passage was computed via Microsoft Word by employing Flesch Readability Ease Score (Flesch, 1948) on a 100-point scale. The score on the scale determines the level of text difficulty which means that the higher the score, the easier the text. Standard documents score range from 60 to 70 (Kincaid, Fishburne, Rogers \& Chissom, 1975). Flesch-Kincaid Grade Level score was also used to determine the appropriate U.S. grade-school level of the reading texts. It ranges from 7.0 to 8.0 for standard documents. Then the statistical significance of semantic, syntactic, and parasyntactic domains and their subcategories was tested via Chi-square test and cross tabulation. SPSS version 22 was employed to run all statistical analyses. 


\section{Results and Discussion}

Considering the level of 15 reading passages of FCE book, Table 1 was aimed at determining the readability level of these passages by running Flesch Reading Ease test. As the table reveals, the reading texts in this book fall within the range of 47.9 (difficult texts) to 74 (approximately standard texts) scores. Additionally, as the table shows reading passages are not organized from easy to difficult. Passage 7 (Value for money) is, for example, easier than all its previous passages and the second passage (Going to extremes) is one of the most difficult texts of the book which is presented at the very beginning of the book. Considering these issues it seems that no readability indices have been taken into consideration to select the 15 passages of FCE.

Table 1

Readability Level of the 15 Passages of Ready for FCE

\begin{tabular}{l|lll} 
NO & TITLE & FLESH & FKGL \\
\hline $\mathbf{1}$ & Handle with Car & 67.7 & 8.5 \\
$\mathbf{2}$ & Going to extremes & 55.4 & 12.2 \\
$\mathbf{3}$ & The Convenience Society, or con for short & 60.2 & 10.8 \\
$\mathbf{4}$ & A walk in the midday sun & 69.2 & 8.3 \\
$\mathbf{5}$ & Home is where the school is & 59.5 & 9.4 \\
$\mathbf{6}$ & Family foods- or just lunch? & 62.7 & 9.7 \\
$\mathbf{7}$ & Value for money & 47.9 & 11 \\
$\mathbf{8}$ & Is your journey really necessary? & 61.2 & 8.7 \\
$\mathbf{9}$ & UFOs- have been visited? & 50.2 & 12.3 \\
$\mathbf{1 0}$ & Private investigators investigated & 59.6 & 10 \\
$\mathbf{1 1}$ & Lucky to be alive & 74.0 & 6.8 \\
$\mathbf{1 2}$ & Water: Are you drinking enough? & 52.9 & 10.5 \\
$\mathbf{1 3}$ & Life in the fast lane & 64.5 & 9.1 \\
$\mathbf{1 4}$ & The most successful living artist & 51.1 & 11.6 \\
$\mathbf{1 5}$ & Two Languages good, three Languages even better & 47.9 & 12.5
\end{tabular}


Regarding Flesch-Kincaid grade level scores, it can be seen in Table 1 above the passages are not homogeneous enough to guarantee the selection of FCE teaching materials based on any objective measures of comprehensibility. For instance, passage 11 (Lucky to be alive), is suitable for grade six students while passage 15 (Two Languages good, three Languages even better) and passage 2 (Going to extremes) are proper for college students.

Table 2 illustrates the types and tokens of subcategories comprising semantic, syntactic, and parasyntactic schemata of FCE reading texts. The results reveal that the FCE reading passages are mainly composed of semantic $(46.7 \%)$ and syntactic $(40.5 \%)$ schema tokens and only $12.6 \%$ of tokens are parasyntactic in the domain. Moreover, this finding reveals that there is a significant difference between semantic, syntactic, and parasyntactic tokens in FEC book $\left(\mathrm{X}^{2}=1704, \mathrm{p}<0.05\right)$.

Table 2

Distribution of Schema Genus "Types" and "Tokens" in 15 Passages of FCE

$\begin{array}{llllllll}\text { Schema } & \text { Genus } & \text { Type } & \text { Type \% } & \text { Total \% } & \text { Token } & \begin{array}{l}\text { Token } \\ \text { \% }\end{array} & \begin{array}{l}\text { Total } \\ \text { \% }\end{array} \\ \text { Semantic } & \text { Nouns } & 1204 & 42.6 & & 2029 & 23.5 & \\ & \text { Verbs } & 569 & 20.1 & & 1186 & 13.7 & \\ & \text { Adjectives } & 413 & 14.6 & & 667 & 7.7 & \\ \text { Syntactic } & \text { Adverbs } & 93 & 3.2 & \mathbf{8 0 . 7} & 146 & 1.6 & \mathbf{4 6 . 7} \\ & \text { Determiners } & 27 & 0.9 & & 1105 & 12.8 & \\ & \text { Conjunctions } & 23 & 0.8 & & 505 & 5.8 & \\ & \text { Prepositions } & 53 & 1.8 & & 946 & 10.9 & \\ & \text { Pronouns } & 52 & 1.8 & & 640 & 7.4 & \\ \text { Parasyntactic } & \text { Syntactic verbs } & 37 & 1.3 & \mathbf{6} & 300 & 3.4 & \mathbf{4 0 . 5} \\ & \text { Abbreviations } & 47 & 1.6 & & 101 & 1.1 & \\ & \text { Interjections } & 0 & 0 & & 0 & 0 & \\ & \text { Names } & 165 & 5.8 & & 220 & 2.5 & \\ & \text { Numerals } & 69 & 2.4 & & 135 & 1.5 & \\ & \text { Para-adverbs } & 66 & 2.3 & & 472 & 5.4 & \\ & \text { Particles } & 2 & .0 & & 156 & 1.5 & \\ & \text { Symbols } & 2 & .0 & \mathbf{1 2 . 4} & 8 & .1 & \mathbf{1 2 . 6}\end{array}$


Nonetheless, the percentage of domains differ noticeably from each other regarding schema types as shown in Table 2 above. In other words, $80.7 \%$ of the texts embrace semantic types, whereas syntactic and parasyntactic schema types constitute only $6.3 \%$ and $12.4 \%$, respectively. This finding is in accordance with that of Khodadady (2008b) and suggests that teachers should spend a considerable amount of time on meaning. This notion can also be profitably used in order to enhance students' reading comprehension because as Wade (1990) mentioned good readers are more meaning oriented.

Table 3 presents the significance of differences found among the three genera types $\left(X^{2}=2869.9, p<0.05\right)$ and tokens $\left(X^{2}=1704, p<0.05\right)$. As can be seen, FCE reading passages benefit significantly from the presence of semantic types (observed $\mathrm{N}=2279$ ) and rest heavily on them. Syntactic (observed $\mathrm{N}=191$ ) and parasyntactic (observed $\mathrm{N}=352$ ) types are both far less than expected $(\mathrm{N}=940.7)$. This finding also suggests that there is a significant different between semantic, syntactic, and parasyntactic types in FEC book which endorses the fact that schema analysis of books can mirror their psychological reality.

Table 3

Chi-Square Test of FCE Reading Schema Domains

\begin{tabular}{|c|c|c|c|c|c|c|}
\hline \multirow{2}{*}{ Schema } & \multicolumn{2}{|c|}{ Observed N } & \multicolumn{2}{c|}{ Expected N } & \multicolumn{2}{c|}{ Residual } \\
\cline { 2 - 7 } & Type & Token & Type & Token & Type & Token \\
\hline semantic & 2279 & 4028 & 940.7 & 2872 & 1338.3 & 1156 \\
\hline syntactic & 191 & 3496 & 940.7 & 2872 & -749.7 & 624 \\
\hline parasyntactic & 352 & 1092 & 940.7 & 2872 & -588.7 & -1780 \\
\hline Total & 2822 & 8616 & & & & \\
\hline
\end{tabular}

\section{Discussions and Conclusion}

This study analyzed Ready for FCE textbook in the light of the microstructural approach to schema theory. This book aims to prepare students for Cambridge First certificate examination which is held all over 
the world to test "candidates' readiness for English-medium vocational and Higher Education courses" (Zeronis \& Geranpayeh, 2015, p.5). The test consists of " 5 main papers each of which carries $20 \%$ of the total and one of these papers is devoted to reading comprehension test" (p. IV). Therefore, students' reading comprehension is one of the main objectives of this test.

Although in new version of FCE test reading comprehension passages emphasize "use of English tasks is on lexical and grammatical knowledge, they, along with Reading tasks, require reading comprehension" (Vidakovich, Elliott \& Sladden, 2015, p. 9). As assessment tools, they require a wide range of cognitive processes. Khalifa and Weir (2009) model of reading comprehension represents the processes as below:

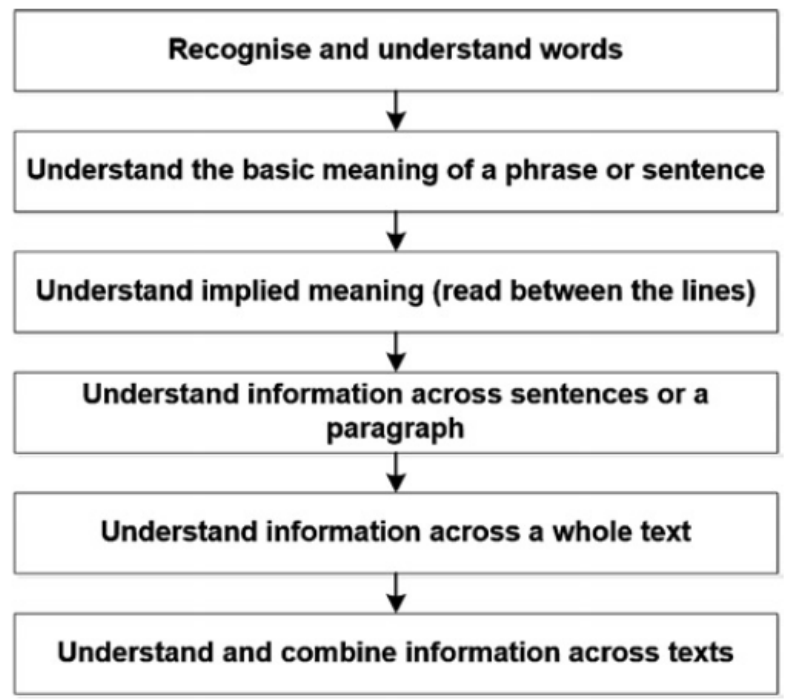

Figure 1. A model of reading comprehension (adopted from Khalifa \& Weir, 2009, p.43).

As shown in figure 1 above, all cognitive processes can be summarized into a microstructural approach dealing with the meanings as well as the linguistic functions of words as they combine with each other to produce texts. In fact, in this view schema is a representative of a specific concept whose comprehension in isolation and in combination with others brings 
about understanding as learners move from the first step of this model to the last. In fact, the microstructural approach can be a theoretically sound method of teaching reading comprehension as documented in Khodadady, Pishghadam and Fakhar's (2010) findings. More importantly, taking schema-based language teaching approach can change students' performance significantly not only on seen texts but also on unseen ones, providing a great help for FCE test candidates. The reason is that reading passages of the FCE tests are assumed to be unseen to their takers.

As was mentioned earlier, the FCE test has been revised for better changes. According to Zeronis and Geranpayeh (2015), one of the key aims of this revision was "reflecting the most up-to-date methodological approach to communicative language testing" (p. 4). The people in charge of revision did not, however, provide any support for their claim. It is not, for example, obvious what they meant by the most up-to-date methodological approach to communicative language testing. The claim sounds unsubstantiated since the only change they made to the test was merging the Use of English tasks with Reading tasks.

Furthermore, Geranpayeh (2007, cited in Docherty, 2015) brought up another shortcoming of the FCE test by stating that the model of language proficiency underlying all Cambridge English exam reviews is based on the notion that "communicative language ability can be divided into different sub-skills and abilities" (p. 15). He argued further that "although an overall language ability exists, language skills (i.e. reading, writing, speaking and listening) and language knowledge or systems (i.e. grammar and vocabulary) can develop differently in each individual and can be measured as separate aspects of language ability" (p. 15). In other words, communicative language ability is nothing but the sum of reading, writing, speaking and listening abilities. Gestalt advocates, however, insist on the fact that whole is greater than the sum of its parts. This implies that learners' communicative language ability is greater than the students' sheer abilities of reading, writing, speaking and listening.

Through the lens of microstructural approach, FCE book encompasses 2822 semantic, syntactic, and parasyntactic schemata which need to be learned in this book. Almost about $80.7 \%, 6 \%$ and $12.4 \%$ of schema types comprising this book are semantic, syntactic and parasyntactic in the 
domain, respectively. The syntactic and parasyntactic schema types are responsible for connecting the semantic schema types together to produce the broader concepts called species which are signified in sentences. Since syntactic and paratsyntactic schemata account for the English grammar, the sum of syntactic and parasyntactic schemata $(6 \%+12.4 \%=18.4 \%)$ and their total division by the percentage of semantic schema types $(18.4 / 80.7=0.22)$ provides the most accurate index of FCE comprehensibility. As an index of text comprehensibility, 0.22 shows that FCE texts are very difficult. This finding lends support to Khodadady's (2008b) study in which the objective theory-driven microstructural approach to textual analysis is suggest to be utilized to analyze materials developed for the objective teaching of the English language.

Comparing the microstructural index of comprehensibility (MICRO) with Flesh Readability Ease Score (Flesch, 1948), it can be seen that MICRO considers linguistic functions of words and their combination to produce texts as well as their meaning. However, Flesh is solely based on average sentence length and an average number of syllables per word. For instance, the following sentences are from the first unit of this book named Handle with Care. (Its Flesch Readability Ease Score (67.7) shows that it is a standard unit.)

After recent accounts of drug-taking amongst teenage models in the care of their model agencies, the catwalk world has come once again under public scrutiny. Jess Hallett used to be a booker taking bookings for models, organizing their itineraries and generally running their lives.

As can be seen, the passage "Handle with Care" is about the modeling industry, which is not a recognized industry in the contexts of Iran and is, therefore, difficult for students to comprehend. Consequently, it seems that the dependence of the score on word length and syllable cannot be the distinguishing features of text difficulty level. Indeed, to determine the difficulty and comprehensibility of a passage there is a need for not only linguistic functions but also semantic meanings of the linguistic elements and their combinations which are the main concepts of the microstructural approach of schema theory (Khodadady, 1997). In fact, there is no room for 
words' meaning or schematata in Flesh Readability Ease Score which is its great weakness and suggests the MICRO superiority.

More importantly, instead of viewing words in terms of their length, the MICRO approaches them as representative of specific concepts whose comprehension in isolation and in combination with each other brings about the understanding of texts such as the FCE reading passages (Khodadady, 1997). This perspective of MICRO is in line with FCE test designers' objective. For instance, "Sometimes it is necessary for students to choose between words with a similar meaning, e.g. choosing 'leaking' rather than 'spilling', 'pouring' or 'flowing' to fill the gap in 'The roof of our tent was..." and, therefore, it is suggested to give learners "practices in recognizing the differences in meaning between similar words, e.g. 'cut' and 'tear"' (http://www.cambridgeenglish.org/exams/first/). In this sense, FCE test deals with schemata rather than memorizing vocabularies because schemata, according to Khodadady (2009), evoke an idiosyncratic image in the mind of a given test taker when he encounters it in a spoken and written text. He also provided the example of leak in the following lines:

But when the results of the tests were leaked last week, Amgen, the Californian biotechnology company which owns the exclusive rights to develop products based on the protein, saw an overnight jump in its share prices.

Khodadady (2009) argued that leak in the sentence above is a schema because it had a definite meaning for the author when he wrote the article Miracle' jab makes fat mice thin (New Scientist, 5 August 1995, No 1989). It must evoke the same meaning in the mind of its readers if they are to understand the article as the author intended them to do. Consequently, "The evocation of an image by a schema depends directly on the semantic and syntactic relations it has with all similar schemata in general and the schemata used in the text in which it appears in particular" (p. 5).

From the cognitive aspect of a microstructural approach, some of the most frequent schemata such as "children" (token of 27), "water" (token=26), and "language (token=18) are discussed here. Children and language are used the most in unit 15 which is named Two Languages good, three Languages even better. Clearly, as the title of this unit suggests it deals with the idea of language learning and that is why the schema of language is 
used the most in this unit. Additionally, "who does the greatest proportion of language learners belong to?" The answer to this question would be more or less limited to children which is used 10 times in this passage.

Another example is the schema of "water" which is used 11 times in unit 4: A walk in the midday sun and 8 times in unit 12: Water: are you drinking enough? There is no surprise that unit 12 is one of the units which is weighed down by "water" schema because the unit itself approves the frequent use of this schema by its title. The question is how is the frequent use of "water" justified in unit 4. As was mentioned before, in the microstructural approach, schemata are considered both in isolation and in combination with each other which brings about the understanding of the text. In this regard, a combination of words like $A$ walk in the midday sun can bring the notions like thirst, sweat, lack or need of water to mind which cognitively prepares the readers mind for encountering the word "water" for about 10 times. As a result, the profound understanding of schemata helps students comprehend the text by focusing on the title.

Therefore, schema can be considered as the basic unit of text analysis as well as teaching materials because it provides the readers and learners not only with linguistic and cognitive domains, genera, species and types represented by texts, paragraphs, sentences and words, respectively, also with their discoursal context as they move from schema types to domains continuously. Based on this interactive process Khodadady (2008b) maintained that schema theory explains how teachers and learners utilize concepts brought up in the textbooks to gain proficiency in a language.

It is also worth mentioning that students' language learning journey can be facilitated by schema-based language teaching (Khodadady \& Hesarzadeh, 2014). As discussed earlier, teaching reading passages by explicit teaching of schemata can deepen students' understanding of reading passages. However, it should not be forgotten that future research is required to find out whether significant differences would be observed on FCE test results of students enjoying schema-based instruction which can be an inspiration to many test designers and material developers. 
18 Khodadady \& Attaran - Evaluation of FCE Reading Passages

\section{References}

Altman, G. T. M., Garnham, A., \& Dennis, Y. (1992). Avoiding the garden path: Eye movement in context. Journal of Memory and Language, $31,685-712$.

Bartlett, F. C. (1932). Remembering: A study in experimental and social psychology. Cambridge: Cambridge University Press.

Breen, M. (1989). The evaluation cycle for language learning tasks. In P. Rea-Dickins \& K. Germaine (Eds), Evaluation. Oxford: Oxford University Press.

Chastain, K. (1971). The development of modern language skills: Theory to practice. Philadelphia: Curriculum Development Center

Daftarifard, P., \& Birjandi, P. (2015). Lower Intermediate Readers and Their Use of Cognitive and Metacognitive Strategies. Sino-US English Teaching, 12(10), 757-761.

Docherty, C. (2015). Revising the use of English component in FCE and CAE. Researchers Notes, 62, 15-20.

Flesch, R. (1948). A new readability yardstick. Journal of Applied Psychology, 32, 221-233. doi: 10.1037/h0057532

Geranpayeh, A. (2007). Using structural equation modelling to facilitate the revision of high stakes testing: The case of CAE. Researchers Notes, 30, 8-12.

Gharbavi, A., \& Mousavi, S. A. (2012). A content analysis of textbooks: Investigating gender bias as a social prominence in Iranian high school English textbooks. English Linguistics, 1(1), 42-49. doi: 10.5430/elr.v1n1p 42

Hakemulder, F. (2006). A third culture: The empirical study of literature, culture, and the arts. In K. Brown (Eds.), Encyclopedia of language and linguistics, (pp. 274-280). Oxford: Elsevier.

Head, H. (1920). Studies in neurology. London: Oxford University Press.

Howden, D., \& Metha, S. (2015). Stakeholder consultation: Review of FCE and CAE. Researchers Notes, 62, 6-8.

Hutchinson, T. \& Waters, A. (1987). English for specific purposes: A learning-centred approach. Cambridge: Cambridge University Press. 
Khalifa, H., \& Weir, C. J. (2009). Examining reading: Research and practice in assessing second language reading. Cambridge: UCLESICambridge University Press.

Khodadady, E. (1997). Schemata theory and multiple choice item tests measuring reading comprehension. Unpublished $\mathrm{PhD}$ thesis. The University of Western Australia.

Khodadady, E. (2001). Schema: A theory of translation. In Training Translators and Interpreters in the New Millennium, Portsmouth 17th March 2001 Conference Proceedings (pp. 107-123).

Khodadady, E. (2004). Schema-based cloze multiple choice item tests: Measures of reduced redundancy and language proficiency. ESP specialist, 25(2), 221-243.

Khodadady, E. (2008a). Measuring translation ability and achievement: A schema-based approach. Quarterly Journal of Humanities, Al-Zahra University, 18(70), 56-76.

Khodadady, E. (2008b). Schema-based textual analysis of domain-controlled authentic texts. Iranian Journal of Language Studies (IJLS), 2(4), 431 448.

Khodadady, E. (2009). Objective-based achievement testing in the context of schema theory. Iranian Journal of Language Studies (IJLS), 3(1), 130.

Khodadady, E. (2013). Research principles and methods and statistics in applied linguistics. Mashhad: Hamsayeh Aftab.

Khodadady, E. \& Herriman, M. (2000). Schemata theory and selected response item tests: From theory to practice. In A. J. Kunnan (Ed). Fairness and validation on language assessment (pp. 201-222). Cambridge: CUP.

Khodadady, E. \& Hesarzadeh, R. (2014). The effect of schema-vstranslation-based teaching on learning English in high schools. Theory and Practice in Language Studies, 4(1),143-154. doi: 10.4304/tpls.4.1.143-154

Khodadady, E., \& Khosravani, H. (2014). Ideology in the BBC and press TV's coverage of Syria unrest: A schema-based approach. Review of Journalism and Mass communication, 2(1), 47-67. 
Khodadady, E., \& Lagzian, M. (2013). Textual analysis of an English dentistry textbook and its Persian translation: A schema-based approach. Journal of Studies in Social Sciences, 2(1), 81-104.

Khodadady, E., Pishghadam, R., \& Fakhar, M. (2010). The relationship among reading comprehension ability, grammar, and vocabulary knowledge: An experimental and schema-based approach. Iranian EFL Journal, 6, 7-49.

Khodadady, E., Shirmohammadi, S., \& Talebi, F. (2011). Brainstorming and Its Effect on Critical Thinking and Speaking. The Iranian EFL Journal, 19, 51.

Khojasteh, L., \& Reinders, H. (2013). How textbooks (and learners) get it wrong: A corpus study of modal auxiliary verbs. Applied Research on English Language, 2(1), 33-44.

Kinciad, j. P., Fishburne, R.P., Jr., Rogers, R. L., \& Chissom, B. S. (1975). Derivation of new readability formulas (Automate Readability Index, Fog Count and Flesh Reading Ease Formula) for Navy enlisted personnel. Research Report 8-75, Millington,TN: Naval Technical Training, U.S. Naval Air Station, Memphis, TN.

McNeil, J. (1987). Reading comprehension: New direction for classroom practice. Blenview, IL: Foresman, and Company.

Norris, R. (2008). Ready for FCE. Macmillan: Macmillan Publisher

Nunan, D. (1987). The teacher as curriculum developer. Adelaide: National Curriculum Resource Centre.

Piaget, J. (1926). The child's conception of the world. New York: Harcourt, Brace.

Poplin, M. S. (1988). Holistic /constructivist principles of the teaching /learning process: Implications for the field of learning disabilities. Journal of Learning Disabilities, 21,401-416. doi: 10.1177/002221948802100703

Purpura, J. E. (1997). An analysis of the relationships between test takers' cognitive and metacognitive strategy use and second language test performance. Language Learning, 47(2), 289-32. doi: 10.1111/00238333.91997009

Rashidi, N, \& Ghaedsharafi, Sh. (2015). An investigation into the culture and social actors representation in Summit series ELT textbooks 
within Van Leeuwen's 1996 framework. SAGE Open, 5(1), 1-10. doi: $10.1177 \& 2158244015576054$

Richards, J. C. (2001). The role of textbooks in a language program. Retrieved from http://www.professorjackrichards.com/pdfs/role-oftextbooks.

Roohani, A., \& Tanbakooei, N. (2012). Evaluating Passages 1 and First Certificate Textbooks: A Discourse Perspective. Research in Applied Linguistics, 3(2), 82-106.

Rumelhart, D.E. (1975). Notes on a schema for stories. In D. G. Bobrow \& A. Collins (Eds.), Representation and understanding (pp. 211-236). New York: Academic Press.

Semino, E. (1997). Language and world creation in poems and other texts. London: Longman.

Sheldon, L. E. (1988). Evaluating ELT textbooks and materials. ELT journal, 42(4), 237-246. doi: 10.1093/elt/42.4.237

Stockwell, P. (2006). Schema theory: Stylistic applications. In K. Brown (Eds.) Encyclopedia of language and linguistics (pp. 8- 13). Oxford: Elsevier.

Tanenhaus, M. K., Spivey-Knowlton, M., Eberhard, K., \& Sedivy, J. (1995). Integration of visual and linguistic information during spoken language comprehension. Science, 268, 1632-1634.

Taylor, B., Harris, L. A., \& Pearson, P. D. (1988). Reading difficulties: Instruction and Assessment. New York: McGraw-Hill Publishing company.

Tomlinson, B., Dat, B., Masuhara, H., \& Rubdy, R. (2001). ELT courses for adults. ELT Journal, 55(1), 80-101. doi: 10.1093/eltj/55.1.80

Toms, C. (2004). General English coursebooks and their place in an ESAP programme. Asian EFL Journal, 6(1).

Tsagari, D. (2011). Washback of a high-stakes English exam on teachers' perceptions and practices. Selected Papers from the 19th ISTAL, 431445.

Tucker, C. A. (1975). Evaluating beginning textbooks. English Teaching Forum, 13, 355-361.

Ur, P. (1996). A course in language teaching: Practice and theory. Cambridge: Cambridge University Press. 
van Leeuwen, T. (1996). The representation of social actors in discourse. In C. R. Caldas-Coulthard \& M. Coulthard, (Eds.), Texts and practices: Readings in critical discourse analysis (pp. 32-70). London: Routledge.

Vidakovic, I., Elliott, M., \& Sladden, J. (2015). Revising FCE and CAE reading tests. Researchers Note, 62, 8-14.

Wade, S. E. (1990). Using think alouds to assess comprehension. The Reading Teacher, 43(7), 442-451.

Zeronis, R., \& Geranpayeh, A. (2015). Continuity and innovation: Updating FCE and CAE. Researchers Note, 62, 3-5.

Ebrahim Khodadady is currently an academic member of Ferdowsi University of Mashhad. He has been offering undergraduate and graduate courses in applied linguistics in Australia, Canada and Iran.

Atena Attaran is $\mathrm{PhD}$ candidate of Applied Linguistics at Ferdowsi University of Mashhad

Contact address: Ferdowsi University of Mashhad, Azadi Roundabout, Mashhad, 91779-48883, Iran. Email: ekhodadady@um.ac.ir 


\section{RIMCIS \\ Social Sciences}

\section{Hipatia Press}

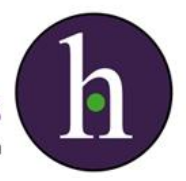

Instructions for authors, subscriptions and further details:

http://rimcis.hipatiapress.com

\section{Women Vulnerability in Informal Entertainment Sectors in Kathmandu: A Human Rights Perspectives}

Ghanashyam Niroula ${ }^{1}$

1) FPAN, Family Planning Association of Nepal

Date of publication: March $30^{\text {th }}, 2017$

Edition period: March 2017 - July 2017

To cite this article: Niroula, G. (2017). Women Vulnerability in Informal Entertainment Sectors in Kathmandu: A Human Rights Perspectives. International and Multidisciplinary Journal of Social Sciences, 6(1), 23-46. doi: 10.17583/rimcis.2017.1928

To link this article: http://doi.org/10.17583/rimcis.2017.1928

\section{PLEASE SCROLL DOWN FOR ARTICLE}

The terms and conditions of use are related to the Open Journal System and to Creative Commons Attribution License (CC-BY). 


\title{
Women Vulnerability in Informal Entertainment Sectors in Kathmandu: A Human Rights Perspectives
}

Ghanashyam Niroula

FPAN, Family Planning Association of Nepal

\begin{abstract}
The objective of the research was to explore the vulnerability of women working in the entertainment sectors towards prostitution and their social problems. Natural calamities, armed conflict or any other social and economic problems make women and girls more vulnerable in Nepal. There is no fixed data on the number of women working in these sectors. Research methods such as key informant interviews and participation in the interaction programs were employed to gather information. It was found that female sex workers on the street in Kathmandu sit in the crowd area of the city. Unemployment and poverty in the urban area have made especially the migrant young women involve in sex profession. Participants in the interview said that domestic violence has made women do anything for their sustenance. The sex worker women suffer from social stigma and reproductive health problems. However, they have hidden their health problems. Finally, due to the orientation and assistance of non-government organizations, the sex-workers have started to organize in groups and are more empowered than before.
\end{abstract}

Keywords: entertainment sectors, prostitution, women and girls, qualitative study 


\section{La Vulnerabilidad de las Trabajadoras Sexuales en Kathmandu: Una Perspectiva de los Derechos Humanos}

Ghanashyam Niurola

FPAN, Family Planning Association of Nepal

\section{Resumen}

El objetivo de la investigación fue explorar la vulnerabilidad y los problemas sociales con que se encuentran las mujeres que trabajan en el sector del ocio enfocado a la prostitución. Las mujeres y chicas de Nepal se vuelven más vulnerables con los desastres naturales, los conflictos armados y cualquier otro problema económico y social. No hay ningún dato definitivo sobre el número de mujeres trabajando en este sector. Para recoger datos se utilizaron métodos de investigación como las entrevistas a informantes clave y la participación en los programas de interacción. Encontramos que las trabajadoras sexuales de las calles de Kathmandu se asientan en el área más poblada de la ciudad. Son el desempleo y la pobreza del área urbana lo que empuja especialmente a las chicas migrantes a ejercer la prostitución. Las personas entrevistadas dijeron que la violencia doméstica ha empujado a las mujeres a hacer cualquier cosa para sustentarse. Las trabajadoras sexuales sufren el estigma social y problemas de salud reproductiva. Sin embargo, ellas esconden sus problemas de salud. Finalmente, debido a la orientación y asistencia de organizaciones no gubernamentales, las trabajadoras sexuales han empezado a organizarse en grupos y están más empoderadas que antes.

Palabras clave: sector del entretenimiento, prostitución, mujeres y chicas, investigación cualitativa 
rticle 3, paragraph (a) of the Protocol to Prevent, Suppress and Punish Trafficking in Persons defines human trafficking as 1 recruiting, taking a person from one place to another by deception, threat, coercion, abduction or giving something to get control of another person for exploitation. The exploitation may be of any kinds, such as sexual, forced labor or removing organs from the human body and the human trafficking constitutes three elements such as the act, the means and the purpose (UNODC, n.d.).

Prostitution is an act of selling a woman body for a sexual purpose to a man. However, it is done voluntarily or involuntarily. Some women do so as a source of income, but many poor women are forced to involve although they do not want to do so. It is estimated that only a handful of them are engaged in prostitution for sensual pleasure. In the poor country like Nepal, women are engaged in forced prostitution because they do not have other alternatives for their livelihood. Similarly, there are also many girls and women in Nepal who are unknowingly landed in the profession.

Since 1950, Nepal has been continuously moving towards political changes. After each change, there has been a slight positive breakthrough in establishing women's rights. After the immense people movement in 2006, women's legal, political, property and some reproductive health rights have significantly established. Nevertheless, till now prostitution is not legalized in Nepal. On one side, women are forcefully engaged or unknowingly involved in prostitution by their job masters and on the other side, police arrest and torture them in the name of maintaining rules and orders. The helpless women engaged in forced prostitution are trapped from both sides. Nonetheless, the commercial sex in the capital city, Kathmandu became more visible after the political change/restoration of multi-party democracy in 1990.

After the 1990s, the Nepalese society became open in many aspects and different entertainment businesses were opened in Kathmandu, the capital city of Nepal. In the capital, there are many massage parlors, cabin restaurants, dance bars, dohori saaj (duet folk songs) ${ }^{1}$ where many women work. These places are termed as so-called entertainment sectors. In these sectors, many women knowingly or unknowingly have landed or are continuously landing in sex profession. The women working in the so-called 


\section{Niroula - Women Vulnerability}

entertainment sectors have a high chance of entering into the sex profession. They are mostly found to be from the poor and rural background. They were unknown about the sex activities that take place inside the hospitality sectors, however, the owner of the business take advantage of their poverty and make them obliged to be involved in sex. In other words, it is a type of internal human trafficking.

Women in the entertainment sectors are low paid and also do not have fixed working hours. It is believed that women offer sex to the customers as their source of income/livelihood or in some cases, just for one meal and shelter for one night. Yet, commercial sex is not permitted by the law of Nepal. In this article, the situation of forced prostitution, the problems of women in these sectors, how do they engage in this sector, their vulnerability and human rights issues, any positive work from any organizations to assist in overcoming from the difficult situation of women, and short terms and long terms solutions to these problems will be discussed.

The general objective of the research article is to explore the vulnerability of women working in the entertainment sectors towards prostitution. More specifically,

a. To explore the chance of women working in the entertainment sectors to get involved in commercial sex/ prostitution

b. To know the work condition and the status of street female sex workers

c. To examine the social and health problems faced by the sex workers and also the difference between general people and sex workers in terms of rights they are enjoying

\section{The Problem}

In Nepal, before 1950, the Rana Prime Ministers from one Clan had owned the country's administrative, political, military, financial and all other forms of power, the rulers were very autocratic and there was no rule of law. In their palaces, many young women in the different names such as girls (Nepali name: keti), servant (Nepali name: sushare), maiden (Nepali name: 
maiya) were recruited in order to provide them entertainment and sexual pleasure. Although the rulers officially had many wives (also called their queens). The young women were exploited according to the rulers' will. These girls were mainly brought from nearby districts of Kathmandu, the capital city. It could also be argued that it was a form of internal trafficking by the rulers (CDPS \& ILO, 2002).

When the Rana regime was abolished in 1950, some powerful Ranas migrated to big cities of India such as Bombay and Calcutta for Nepal. They took the women with them. Unfortunately, when the Ranas settled in India kept young women with them and sold the old women to the brothels for money (ibid). Again, when the trafficked women from Indian brothels came to see their parents in Nepal, they started taking other girls luring by fake promises of good life and attractive salary. The chain of cross-border trafficking continued, the government also could not control it because the government officials, police were purchased or given bribe by the brokers or traffickers.

After re-installation of democracy in 1990, huge campaigns were organized by women activists, civil society members and human rights activists to stop cross-border trafficking and there was also awareness programs in different places throughout the country. The media like TV/ radio disseminated and broadcasted information against trafficking and also the ways for self-protection which helped in reducing the number of crossborder trafficking.

However, after the six years of re-installation of democracy, a left winged revolutionary communist party called Maoist started a civil war against the Government in order to establish Nepal as a Communist republic and there was an armed conflict between the Government and the Maoist. This battle adversely affected the poor people. Both the agitating parties put the poor people in torture and insecurity which resulted in an increase of internal displacement from the remote areas to the capital city in search of security and livelihood.

Among the displaced people, women, children and especially the girls were more affected. The illiterate and helpless women started to search jobs in the city. They did not get jobs because they were unskilled and were bound to work in the hospitality sectors also so called entertainment sectors, 


\section{Niroula - Women Vulnerability}

although they were not fully informed about the activities that used to happen inside there.

The government of Nepal has classified different workplaces as informal entertainment sectors in Kathmandu such as massage parlor, cabin restaurant, dance bar and dohori saaj (duet folk songs) ${ }^{2}$ centers. Dance bar and dohori saaj are open only at night, however, massage parlor and cabin restaurant business are run during the daytime. It is found that the owners of these business centers have recruited under aged girls to attract the clients, and most of them girls and women who work there are illiterate. There is a high chance of exploitation of those girls and women because of their poor economic condition and lack of knowledge. They are recruited by their owners to work as a crew only however, they are obliged to work as sex workers.

The women and girls do not want to work as the sex workers but they are forced and compelled to obey their job masters in order to survive. The main reason which has pushed them into forced prostitution is their economic vulnerability. The so-called entertainment sectors consumed more vulnerable women as the workers and the owners of such sectors exploit them through different ways including rape, sexual assault and involving in forced prostitution. Although almost all of the women are working for their livelihood and bring up their children, but the society has stigmatized such populations as immoral and worthless. People blame them to be valueless. They have no options. They are socially, economically, mentally and psychologically deprived and distressed. This is the main problem.

The campaigners and organizations which work for the rights of women workers claim that the owners of entertainment sectors in Kathmandu are powerful and have a nexus to police and politician. They further assert that with the silence support of powerful authorities the owners are running illegal sex business to make more money. It is an irony and injustice that the girls and women who are recruited for hospitality service provider purpose are forced to work as sex workers. Unfortunately, the girls are not preinformed about their job conditions and do not have any job contract papers. It is a duty of any owner to provide clear information regarding job descriptions, working hours and payment. An employer cannot involve any worker against the prevailing law of the country and also cannot violate 
human rights of any individual worker. Nevertheless, the owners of the entertainment business in Kathmandu are acting against the law and also defying human rights of women workers.

Culturally, in Nepal, the role of a woman is subordinate to male and their voice is unheard or is not taken seriously. It is seen that in the case of any difficulty or sufferings inside a family, females suffer more than males. However, in the harsh situation also, the males suffer less than females and still enjoy some facilities. During the very difficult time throughout the ten years long internal conflict (1996-2006), poverty and unemployment made women and girls work in the so-called entertainment sectors. Due to the vulnerability of women, lack of legal punishment and impunity to the business owner who exploits women also made the situation favorable to increase prostitution in the Kathmandu city.

\section{Review of Situation of Women Working in Entertainment Sectors}

Tandon et al. (2014) explain prostitution is dangerous; it affects vulnerable women and also insults their dignity. There are two perspectives on prostitution. First, it is a consequence of trafficking, violence, and exploitation and second, it happens in mutual consensus between two adults for money or valuable things. Pescinski (2015) categorized trafficking mainly as sex trafficking or labor trafficking and it is not easier to get actual statistics on trafficking. However, the two categories of trafficking overlap also because those who are trafficked for labor in restaurants are also forced to involve in sex work. Sex trafficking is merged with prostitution which is not morally accepted by the society.

The sex workers suffer from harassment, abuse, and rape and sometimes are denied to access from basic health facilities and housing. The woman who is forced to sell sex is not a sex worker; she is a trafficked woman and deserves protection. The injustice and discrimination against sex worker should be stopped and those people who abuse or exploit sex workers should be criminalized. But ironically the laws which criminalize brothel keeping and promotion of sex trade, in reality, prosecute or arrest the women who are trafficked and being coerced to work as a sex worker (Murphy, 2015). 


\section{Niroula - Women Vulnerability}

Despandhe et al. (2013) claim that sex trafficking and prostitution are not same things. Sex trafficking is an umbrella term which denotes prostitution, pornography, live sex shows, military prostitution, and sexual tourism. Traffickers or the pimps recruit potential victims who are socially and economically vulnerable. The victims are likely to suffer from different physical health problems such as sexually transmitted disease, and physical injuries. Similarly, they also suffer from psychological trauma, stress, depression and suicidal thoughts. Willis et al. (2016) claim that two very critical health risks and human rights issues of sex workers around the world have been neglected; maternal mortality and morbidity among female sex workers and the health and well-being of the children. Many female sex workers have a chance of high mortality due to HIV/AIDS and complications of unsafe abortion. Globally, a large number of sex workers are a mother and their children are at high risk for HIV, syphilis, and tuberculosis.

In the past, Nepal has had a sex work but today Nepal has a sex industry. Only in Kathmandu city, the capital of Nepal, it is estimated that there are 11.000-13.000 girls and women working in the entertainment industry. All the girls and women who work in those places are not sex workers, however, those who do not sell sex are placed in such situations in which they are subjected to sexual harassment and abuse so that the customers will be pleased and buy food and alcohol (Frederick et al., 2010). Sunar (2014) depicts that sex workers prefer to work in the entertainemt sectors instead of sitting on the street for selling their body because they will be safe from police and also could make more money. Most of them are illiterate and do not have knowledge about pros and cons of being involved in sex profession and later they will be either HIV infected or suffer from social trauma (Sunar, 2014).

Nepali women are also trafficked to cross border countries for the sex trade. The human trafficking act of Nepal has categorized forced prostitution as a crime and the act has also stated the act of involvement in sex and human organ transplantation as a crime. In the fiscal year 2013/14, the women cell of Nepal Police investigated 185 cases of sex and labor trafficking whereas the number of the case was only 144 in the preceding fiscal year. Mostly it is being accused that the political cadres and the police 
officers have investment over the places where sexual activities are performed such as dance bars, however, no direct evidence has been found (U.S. Embassy in Nepal, n.d.).

In a study conducted by ILO in three major cities of Nepal (Kathmandu, Biratnagar, and Pokhara) clearly indicated that the working environment in the entertainment sectors for women and girls is not good. They are low paid, work more hours and endure sexual harassment and abusive treatment from their employers and customers. They said that their salary is not paid on time. Most of the women and girls during their interview reported that they do not encourage others to work in such places. They further opined that are not satisfied by their jobs because the society looks down upon their jobs (ILO, 2006).

The report of National Human Rights Commission (NHRC, 2012) imparts that in Nepal the major areas of human trafficking are: internal trafficking (in the entertainment sectors, brick kilns and in embroidering industries), cross-border trafficking to India and beyond India. Human traffickers take the people for organ transplantation to India and also take in the name of marriage to Korea and Hong Kong. The actual number of women/girls working in the entertainment sectors is not recorded in Kathmandu valley and the trafficking of girls/women in the entertainment sector and their exploitation has been documented since 2000 .

In the survey conducted by Raksha Nepal in 2006, it was found that $71 \%$ worked in massage parlor followed by dance bar (27\%) and guest house (2\%).The majority of the respondents $91.5 \%$ were between the ages of $15-28$ years. Likewise, among the women working in massage parlors, $60.5 \%$ said that they were involved in sexual activities. Similarly, $20 \%$ women working in dance bar and $2 \%$ of women working in cabin restaurant accepted that they were involved in sex profession. The ILO estimate indicates that majority of women and girls are trafficked for commercial sexual exploitation (98 per cent). The young women are trafficked across hidden border. They suffer from exploitation, deception, coercion, and violence. (ILO, n.d.).

Natural calamities or any other troubles in the rural areas may lead to internal or international trafficking of women because the desperate people may easily trust the brokers or the criminals. From this, it could also be said 
that the root cause behind the trafficking or exploitation is poverty (Shakti Samuha, 2013). Due to the lack of skills, education and other income generating opportunities the rural girls who had come to Kathmandu due to the armed conflict had landed up in the entertainment sectors such as dance and cabin restaurants. The girls are extremely vulnerable to sexual abuse and exploitation in such places (Saathi, n.d.).

A report of CWIN (a non- governmental organization) tells that there also have been some studies from the government sides. For example, two studies ordered by the Supreme Court and conducted by the Government of Nepal in 2008 disclosed that there were nearly 1,200 massage parlors, dance bars, and cabin restaurants in Kathmandu alone. The studies found that about 50,000 working in the sectors, out of which $80 \%$ were women, aged 12 to 30 years. It was estimated that among them $50 \%$ of them suffer from some form of exploitation and 9,000-15,000 of them were underaged (CWIN, n.d.).

\section{Research Methods}

Generally conducting research on women issue is not easier in the culturally not open country such as Nepal. Moreover, speaking and doing research on the issues of sex, sex worker, and prostitution is extremely complex. It is very difficult to find the respondents or participants to take part in such research. The research was only focused on qualitative study and among qualitative research methods; Key Informant Interview with key persons who have been working with the women of informal entertainment sectors for more than ten years was considered the most suitable technique to gather detail information on such sensitive topic. Hence, based on their more than ten years of experience, the researcher chose three key informant women who are currently working in the leading NGOs (which work for the rights of women workers of entertainment sectors) in Kathmandu.

At first, the researcher talked with the three selected KIs and informed about the research and its objectives. They were asked to be the KIs and take part in the research and share detail information. The KIs were informed by the researcher that their name will not be disclosed and they will not receive any financial incentives except a big thank you from the researcher. The KIs 
agreed on it, their voice was not recorded however, the researcher noted down their points in his notebook.

It was really very difficult to get information from many sex workers. However, detail information about the subject matter was collected from the key persons who had long experience with the sex worker during different empowerment and advocacy programs. The number of the key informants was decided until the researcher felt saturation or he got the right information, three key informant women were interviewed.

Similarly, the researcher also took part in two different interaction programs and workshop to gather information as a participant. The researcher during the research had been working as a staff of one NGO in Kathmandu. Thus, it was easier for the researcher to attend the interaction program and workshop as a guest. These types of participation helped the researcher to know the issues in depth and also became able to clarify the confusions immediately through questioning. Finally, the interviews and the discussions over interaction programs are analyzed in the research to come in conclusion.

Moreover, the researcher had attended one interaction program of an NGO who work with female sex workers in Kathmandu. In the program, women working in the entertainment sectors such as massage parlor and cabin restaurant openly expressed their opinions why and how they got compelled to involve into forced prostitution. The discussion points are also included in the research to analyze the objectives of the research. Similarly, the researcher also participated in another interaction program which was organized by an organization about to discuss the child vulnerability to trafficking after the big earthquake of Nepal in 25th of April 2015. The important discussion points of the program are mentioned to analyze and understand the situation of internal trafficking issues.

Most importantly, there was a workshop to discuss violence against women working in the entertainment sectors of Kathmandu, there was the participation of as many as thirty women working in those sectors. Among them, thirteen women had openly put forward their problems. The discussion points and the problems presented by women are also discussed and analyzed in the research. 


\section{Demographic Information of the Key Informants (KIs)}

Three Key Informants (KIs) were chosen to collect information about the situation of women workers in the informal entertainment sectors such as massage parlor, dance bar, cabin restaurant and dohori saaj and also about the sex workers in Kathmandu. The three KIs were working in the NGOs for more than ten years and all of them were females; they had their educational level ranging from primary to intermediate levels and were aged between 34 to 43 years. Females were chosen as the KIs because without them it would not have been possible to gather information.

\section{Details of the Information Collected}

The information collected is presented in this section which contains a transcription of three Key Informants' interview, discussion details of the interaction programs and workshop where the researcher attended.

\section{Key Informant Interview Transcription}

\section{key informant no : 1}

It is difficult to say about the exact number and workstation of sex workers in the capital city, Kathmandu of Nepal. It is also not easy to know where they live. Usually, they are found in many places. Some of the sex- workers are found in Ratna Park and some also in front of Bir hospital. They are available in day and night time and charge the sum Rs 100-5.000 depending upon the customers.

Some of them are found in Thamel, in front of the office of the Sanchaya Kosh (provident fund) building and some are found in Naya bazaar town planning, falful chowk (fruit center). Some of the sex-workers sit in rented flats. However, they often migrate from one place to another. If their neighbors know about their businesses they move to another place.

The sex workers are reachable through contact and circle of similar people. They may be contacted through a mobile phone and friends. They sit in different places such as tea shop, a small shop selling beetle and a 
cosmetic shop. Likewise, the women who work in massage parlor are also engaged in sex profession. The customers who come to take service of massage make contact with the women and girls in their regular visits and do sex in the massage parlor. In terms of charging amount, the women negotiate with the customers.

There will be no forced sex in dance bar because some girls dancing in the bar are drugs addict; they also have more income than others. They do not tolerate abuse and may hit when somebody tries to abuse them. However, those girls who work in cabin restaurant have low income. Their salary is between 2.500-3.000 rupees per month and gets more tips from the owner if they are able to procure the customers. Large numbers of cabin restaurants are in Kalimati, Rabi Bhawan and Koteswor area near BNB hospital. There is also sexual exploitation in the cabin restaurant.

Moreover, sex workers are also found in garment industries. Nowadays many sex workers are found in Khaja pasal (a place where snacks are prepared to serve the customers). In $95 \%$ of the Khaja pasal, most of the women sit for commercial sex and even some people sell the bodies of their own wives for income. Some women serve sex for more than 30 people a day.

\section{key informant no : 2}

The key informant work for the NGO and her duty is to identify new sex workers who have recently landed in the same field and she also does regular STDs check up for the sex workers in the Kathmandu. Her duty station is from Ratnapark, Tripureshwor, Kalimati to Balkhu. She said that she could identify the new SWs when she speaks with them for three times. In a question, how does she know them, she replied that through the language, gesture of eyes and through her walks.

She said there are about forty sex workers in the Ratnapark area and they only sit at day time. There are other women who only sit there at night and the number of such women sitting at night is about thirty. The age group of women sitting at Ratnapark differs. She claimed that there are about 6-7 girls below the age of 16, other are mid age between 25-40 and some are also between the age of 50-60. 
The researcher also asked the key informant about the rate they charge to the clients. She said that the minimum rate is 1000 rupees. She also said that if a Sex worker goes with a client in 500 rupees only, then she will be beaten by other SWs. When the client and the women agree at the price, then the SW will take the client to the guest house either in Sundhara or Bagbazzar where they have to pay half the amount to the owner of the guest house where they will have regular contact.

Some of the SWs have rented houses in cheap places, such as, the houses that have been cracked by the earthquake where they take their clients. However, they could not run their businesses in the place for a long time because if the neighbors or the house owner are informed about their businesses then they would have to move from that place. She also informed that there are many newcomers who joined the sex work profession from the mid hilly region of Nepal.

\section{key informant no: 3}

The women who work in the massage parlor and cabin restaurant have different problems. They do not want to share all their information with everybody. Sometimes, when they are depressed or in trouble then at that time they share something to the women whom they have known for a long time.

Most of the women who are involved in sex profession for a long time have serious reproductive health problems. For example: when they come near other people they smell very bad. So, they hesitate to go near unknown people thinking that they may know their profession. Moreover, they do not also go to the doctor because they do not want to share their history.

The women who are engaged in sex profession have psychological stress also. Many types of customers come to fulfill their sex desire with them each day. They are always worried that their male relatives may also come to their workplaces because they never inform anybody that they are working in such professions.

Some women who have worked in the massage parlor for many years have a good income. They have become owners of the business and have recruited young women for the job as workers. Mostly the women who work 
in these sectors invest money in their children education hoping that they do not want their children's future similar to theirs.

From the three key informants' interviews, it could be inferred that there is a violation of women and girls' human rights seriously inside the entertainment sectors. For example, the first key informant said that the girls who work in cabin restaurant are low paid and are sexually exploited. It is an injustice to pay anyone below the national minimum payment level and to exploit somebody sexually. However, the key informant informed that the pay was merely between 2.500-3.000 rupees. This is a serious human rights issue. Similarly, the second key informant said that some sex workers are below the age of 16 years. It is against the international law to involve or abuse anybody below the age of 18 years in any type of work because anyone below the age of 18 years is considered as a child. However, it is learned that some sex workers are below the age of 16 years. It is illegal, distressing and a crime.

In addition to this, the third key informant said that working in entertainment sector do not want to share where they work. They are also in stress and have psychological and reproductive health problem. It can be concluded that being not able to clearly share about the own job to others will surely induce a great humiliation in one's mind which is a kind of psychological trauma and frustration. Overall, the situation of women working in the entertainment sectors seems to be a big human right issue. Moreover, sex profession in Nepal is illegal, in this condition the women have adopted such profession for fulfilling their basic needs. They are always in fear and upset mind.

\section{Details of the Interaction Program}

\section{First Interaction Program, Addressing Child Labour Vulnerability in Post-Earthquake}

The researcher had participated in a program on the second week of June 2015 in Kathmandu, which was about the child vulnerability after the big earthquake of April 25. There were 30 participants from different NGOs and most of the participants expressed serious concerns and worry about the 
trafficking of young girls from the most earthquake affected twelve districts of Nepal. Some people said that new people had reached the quake-hit areas in the name of relief distribution to take the girls out from those areas.

Similarly, some claimed that even the traffickers lured the parents through money and fake promises for their children's bright future. So, the parents themselves help to take the children out from their villages so that the police would not suspect and would also be easier to hide the issue from police.

If the traffickers become able to take children from the villages through fake promises, then it is trafficking. The children may be exploited inside the country or trafficked to India. In most of the cases, it is found that the internally trafficked children become victims of sexual exploitation and finally bound to work in the vulnerable sectors where there is a very high risk to fall prey of sexual exploitation.

\section{Second Interaction Program}

There was an interaction program on last week of July 2015, organized by the USAID-funded project in Kathmandu and there were about 12 participants to discuss gender-based violence and the issue of a sex worker.

Among them, half of the women said that sex workers want rehabilitation and if they get alternative livelihood they would leave their sex profession.

However, among the participants, some argued that all of the sex workers do not have similar behavior. They opined that all sex workers do not want to remain in a rehabilitation center. Some sex- workers may leave the rehabilitation center because they want free life and do not want to remain inside the boundary of a house.

One of the rehabilitation centers operating social worker said that her organization is providing skills to the sex workers. But the social worker further said that her organization will only provide skills to the sex-worker who really want to quit that profession and live a common life like other general people. 


\section{Workshop with Policymakers/Stakeholders on Violence against Women Working in the Informal Entertainment Sectors}

There was an interaction program with women working in the entertainment sectors, female sex workers, police officer, lawyer, journalists and stakeholders such as massage parlor union representative on the second week of November 2015. More than a dozen women openly put forward their problems and opinion in the program. Among the participant women, most of them were working in the entertainment sectors such as cabin restaurant, massage parlor, dohori saaj center (duet folk songs), Khaja pasal (snacks house) and one-quarter of them were female sex workers who sit in the street.

In the workshop, women pointed out some sensitive issues relating to human rights, their problems and how they are harassed by the police. One woman who works on the street as a sex worker said that at midnight while she was on the street, a police caught her and put in custody for seven days. She did not get any food to eat while in the custody. She was also asked for NPRs 10,000 as fine. However, in the law of Nepal, police has no right to (could not ask) demand fine, unless the case is filed in the court for any offense (only the court could ask if necessary). Another woman said that police took their photos and also intimidated to make public if they do not offer them money. This seems a severe case of violating human rights issue.

Most of the women said that police come to their workplace and insult them calling bhalu (derogatory slang word in Nepali to the prostitutes) in front of their customers or relatives. One woman aged nearly fifty years said that her husband is paralyzed and have no alternatives so she comes to the street to make money, however, she said she is insulted by her house owner, police and other people. She opined that she does not want to be a prostitute, but she does not have other alternatives to bring up her children and to buy medicines for her husband.

One woman working in the Khaja pasal (snacks shop) said that police come and sleep with them and again disgraces them as prostitutes. One of the participants said that police come at their workplaces to raid and directly push them into the corner. However, one woman working in the massage parlor said that she has been working in the place for twelve years, educated 
her girls up to higher secondary level through the income and she denied to call her profession to be illegal and bad.

During the workshop, one participant clearly said that if the entertainment sectors will be closed by the government then all the females working in the sectors will come to sit in the street because they have no other option. Overall, women said that they are working in those places or involved in prostitution because of lack of skills and possible alternatives. Some even said that they neither work as laborers nor do hard physical work, so they have chosen this profession. One of the participants argued that all of the women working in the entertainment sectors are not involved in prostitution.

\section{Evaluating the Problems of Women Workers in Human Rights Perspective}

The constitution of Nepal 2015 in the section of fundamental rights article 17.2(f) has clearly stated that a citizen has a right to run the business according to his/her will unless the business is considered illegal or unethical. Furthermore, the supreme court of Nepal has made directives in 2008 to regulate the entertainment sectors and manage the rights of the workers in those sectors. Hence, it is clear that running an entertainment sector business and working in these sectors is legal.

The women and girls work in the cabin restaurant, dance bar and massage parlor in Kathmandu. These are hospitality and entertainment sectors; the females work there in order to generate income for their livelihood. However, they are not able to inform their relatives and friends about their workplace because generally people in Nepal rate these sectors as a place for entertainment or sex profession. In other words, these sectors are not considered as prestigious in Nepal.

Moreover, unfortunately, these females' families also do not ask about their job and source of earning. Mostly, those women, whose economic condition is poor and have no alternatives, enter these sectors for livelihood. The family members know that if she does not work, they cannot get food. In this way, the parents or family members have hidden the pain or sufferings inside their heart even being informed about the nature of her job. 
On one side, the female is exploited by the owners and customers and on the other side, they are blamed as a prostitute from the society. They are working as workers in the hospitality sectors without job appointment letter, fixed salary and also do not have fixed working hours. They are exploited physically, economically and mentally. It is a big issue of human right and their rights to live as a citizen that has been violated.

Similarly, the sectors which provide hospitality and entertainment services such as massage parlor, cabin restaurant, and dance bar could run their businesses only after registering in the government body. Although the businesses are registered in a government office, pay tax but are often raided by the police. Surprisingly, the police, during the raid, take only the female workers but do not touch the business owner.

In addition to this, the female workers blame that when police find a couple indulging in sex at the spot only the girl is arrested but the male member is released without any action. The women argue that it is a kind of violence against them. The women also complained that the police disgrace and insult them publicly through filthy and abusive words. If this allegation against police makes sense, then it is a serious violation of human rights.

Prostitution is not legal in Nepal and keeping sex relationship outside marriage tie is considered unethical. However, in a survey of Raksha Nepal in 2006, it is said that police and army are the major customers of sex workers in Kathmandu. Even in the in-depth interview with the key informants, they said that army and police personnel often come with the girls and women for sex as customers. Although, the women working in the entertainment sectors complain that police often harass them asking for a bribe. To sum up, it could be said that there are unfair activities from the police side whose duty is to maintain and regulate law and order, but they themselves are acting against the human rights.

The Constitution of Nepal 2015 states that everybody has a right to live a healthy life and be healthy throughout the life (Constitution Drafting Committee, Constituent Assembly Secretariat, n.d.). Notwithstanding, the female sex workers either working on the street or in the entertainment sectors do not have a sound health. Although, they earn money for their living but they cannot explain their health problems to others. They think that if they share their health problems to their friends or relatives they will 
be considered as characterless women. So, they are reluctant and not confident in sharing their health problems to others. One of the key informants shared that the sex workers body stinks when they sit near other persons, moreover, their reproductive health problem is serious.

In the workshop, the women said that they want to work in those sectors no longer if they are provided an alternative. It is a duty of a government to provide some alternatives to solve the problems of women. However, the government is doing nothing to protect the rights of a woman to live a decent life.

Finally, it seems that no one has followed and taken sincerely about the concerns of the human rights regarding those working in the entertainment sectors. Although they are working legally, their rights to live as a citizen has been evaded because they are helpless, stigmatized and dishonored socially and culturally.

\section{Conclusions}

The study was concentrated on to explore the vulnerability of women working in the entertainment sectors towards prostitution and also to know the work condition and the status of street female sex workers. Moreover, the study also endeavors to evaluate the social and health problems faced by them. It was designed in a qualitative research framework comprising of three Key Informant interviews and attendance at the interaction programs and workshop to gather information. The researcher was solely responsible for interviewing the informants and participating in the programs and workshop.

It is not clear yet the actual number of women working in the entertainment sectors and hospitality sectors such as cabin restaurants, dance bar, massage parlour, khaja pasal (snacks shop), dohori saaj (duet folk songs) and hotels because the girls and women working in these sectors do not remain in the same place for longer period. Similarly, the exact number of street female sex workers is also difficult to estimate because they are mobile and frequently changing their station.

Through the information collected by the researcher, it was found that most of the women either working in the entertainment sectors or on the 
street for commercial sex have fallen prey to violence inside their families. They are obliged to involve in sex profession for their livelihood in the absence of other income generating sources. So, if the women in the rural areas or in the poor family background are treated equally as a male in terms of social, economic and cultural atmosphere then there will be very few number of woman obliged to sell their bodies.

Although commercial sex or prostitution is not legal in Nepal but it is happening in many places in a hidden way. There is no fixed place where this happens. However, in Kathmandu, it is common inside places such as massage parlor and khaja pasal (snacks shop). In many places of Kathmandu, women working in cabin restaurants and hotels also are involved in sex profession; they go to the places where the customers take them for sex.

Street female sex workers usually wander in the Ratna Park ${ }^{3}$, Bir hospital, and Thamel ${ }^{4}$ areas during the day and night time in search of the customers. They take the customers for sex to the guest house or lodge in the surrounding areas where they have regular dealing with the owners. Moreover, Gongabu ${ }^{5}$ and the new bus park area of Kathmandu are the common places where the sex workers are found.

The relation between the police and the women workers of entertainment sectors seems to be strongly opposed. The women have complaints towards the police, they said that the police insult and humiliate them as prostitutes. However, women workers insisted that all of them are not prostitutes. They are obliged to work there for their sustenance and further argued that if they are given the option for their livelihood they are ready to quit their current roles.

No doubt, a woman should get an opportunity to live as a responsible citizen of a nation by doing any job according to her will or run a business for sustaining her life. It is a serious issue of human rights to be insulted or degraded in a society for working in any legal sector authorized by the government. Either the government should not give permission to run the business or should regulate and manage the sector providing security and maintaining the dignity of the workers.

Furthermore, women have an opinion that they want no longer stay in the job of massage parlor and restaurant it is only their compulsion in the 
absence of other options. A little portion of the women also argued that it is not a bad job because they have educated their children and maintained livelihood expenses from the same job. However, key informants in the interview informed that the women working in the entertainment sectors and sex workers of the street will not easily quit their profession because it is a source of easy money without hard work. Once, even if they are rehabilitated they will again return to the previous job.

To sum up, culturally Nepali society does not give permission to commercial sex and even at present the society has not become open and free to make prostitution legal for commercial purpose. Most of the women who are obliged to sit in the street for exchanging sex for money are either due to the violence from their husbands or due to the lack of livelihood opportunities. In addition to this, some of the girls and women working in the entertainment sectors are also the victims of internal trafficking. The reason behind internal trafficking is also poverty and lack of awareness. Hence, until the poverty and low status of women in the society remain as the unsolved problems in Nepal, the situation of hidden commercial sex as a social problem never comes to end.

\section{Notes}

${ }^{1}$ dohori saaj (the restaurant where duet folk songs are sung for entertaining customers)

${ }^{2}$ dohori saaj (the restaurant where duet folk songs are sung for entertaining customers)

${ }^{3}$ Ratna park (a place of Kathmandu city)

${ }^{4}$ Thamel (a tourist centre of Kathmandu city)

${ }^{5}$ Gongabu (a place near new bus park of Kathmandu city)

\section{References}

Central Department of Population Studies \& International Labour Organization (CDPS \& ILO) (2002). Text for Population and Social Justice Master of Arts in Population Studies. Kathmandu: Central Department of Population Studies, Tribhuvan University Nepal.

Child Workers in Nepal (CWIN) (n.d.). Child Trafficking in Nepal. Retrieved from http://www.cwin.org.np/ 
Constitution Drafting Committee, Constituent Assembly Secretariat (n.d.). Constitution Bill of Nepal Revised Draft 2015 (Unofficial English Translation). Retrieved from http://www.inseconline.org/

Despandhe, N., \& Nawal, M.N. (2013). Sex Trafficking of Women and Girls. NCBI Reviews in Obstetrics \& Gynaecology, 6(1), e22-e27. doi: 10.3909/riog0214

Frederick, J., Basnyat, M., \& Aguettant, J.L. (2010). Trafficking and Exploitation in the Entertainment and Sex Industries in Nepal. A Handbook for Decision Makers. Kathmandu: Terre des homes Foundation.

International Labour Organization (ILO) (n.d.). Women and men migrant workers: Moving towards equal rights and opportunities. Retrieved from http://www.ilo.org/

International Labour Organization (ILO) (2006). A Study of Girls and Women Employed in the Restaurants of Selected Cities of Nepal. Retrieved from http://un.info.np/

Murphy, C. (2015, August 19). Sex Workers' Rights are Human Rights. Amnesty International. Retrieved from https://www.amnesty.org/

National Human Rights Commission (NHRC) (2012). Trafficking in persons especially on women and children in Nepal. National Report 2011. Retrieved from http://www.nhrcnepal.org/

Pescinski, J. (2015, February 2). A Human Rights Approach to Human Trafficking. Our World. Retrieved from https://ourworld.unu.edu

Raksha Nepal (2014). Raksha Nepal's ten years. Kathmandu: Raksha Nepal, Lainchaur.

Saathi (n.d.). Creating a safe and violence free environment for women working in the entertainment sector. Retrieved from http://www.saathi.org.np/

Shakti Samuha (2013). Risk of human trafficking is high. Retrieved from http://shaktisamuha.org.np/

Sunar, G.B. (2014, January 26). Sex in the City-Oped. The Kathmandu Post. Retrieved from http://kathmandupost.ekantipur.com/

Tandon, T., Armas-Cardona, G., \& Grover, A. (2014, October 21). Sex Work and Trafficking: Can Human Rights Lead Us Out of the 
46 Niroula - Women Vulnerability

Impasse? Health and Human Rights Journal. Retrieved from https://www.hhrjournal.org/

United Nations Office on Drugs and Crime (UNODC) (n.d.). What is Human Trafficking? Retrieved from https://www.unodc.org/

U.S. Embassy in Nepal (n.d.). 2015 Trafficking in Persons Report in Nepali. Retrieved from https://np.usembassy.gov/

Willis, B. et al. (2016). Health of female sex workers and their children: a call for action. The Lancet Global Health, 4(7), e438-e439. doi: 10.1016/S2214-109X(16)30071-7

Ghanashyam Niroula is Behavior Change Communication \& Gender Equality and Social Inclusion Specialist at FPAN, Family Planning Association of Nepal.

Contact address: Family Planning Association of Nepal. Central Office, Pulchowk, Lalitpur. P. O. Box 486, Kathmandu, Nepal. Email: nir.ghanashyam@gmail.com 


\section{RIMCISS}

\section{Hipatia Press}

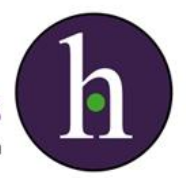

Instructions for authors, subscriptions and further details:

http://rimcis.hipatiapress.com

\section{Sustaining Ghana's National Health Insurance Scheme Through Preventive Healthcare Strategies and Legislation}

Samuel Adu-Gyamfi ${ }^{1}$, Aminu Dramani ${ }^{1}$

1) Kwame Nkrumah University of Science and Technology, Ghana

Date of publication: March $30^{\text {th }}, 2017$

Edition period: March 2017 - July 2017

To cite this article: Adu-Gyamfi, S., \& Dramani, A. (2017). Sustaining Ghana's National Health Insurance Scheme Through Preventive Healthcare Strategies and Legislation. International and Multidisciplinary Journal of Social Sciences, 6(1), 47-69. doi: 10.17583/rimcis.2017.2149

To link this article: http://doi.org/10.17583/rimcis.2017.2149

\section{PLEASE SCROLL DOWN FOR ARTICLE}

The terms and conditions of use are related to the Open Journal System and to Creative Commons Attribution License (CC-BY). 


\section{Sustaining Ghana's National Health Insurance Scheme Through Preventive Healthcare Strategies and Legislation}

Samuel Adu-Gyamfi

Kwame Nkrumah University

of Science and Technology
Aminou Dramani

Kwame Nkrumah University

of Science and Technology

\section{Abstract}

This article focuses primarily on secondary literature to highlight some of the key issues that has affected the effectiveness and the efficiency of the National Health Insurance in Ghana. The article proposes the need to use legislation and additional preventive healthcare strategies to lessen or reduce the pressure that comes upon the National Health Insurance Authority. Finally, it postulates that the people of a community, their institution, that is health institutions and Para-health institutions that ensure public safety, environmental protection, and sanitation among others are enjoined to reduce the occurrence of disease and injury or harm. This could ensure a healthy work force and a healthy population that has the tendency or proclivity to increase productivity and lessen disease burden with its associated harm and cost on the state, especially in countries where social insurance is practiced.

Keywords: National Health Insurance (NHIS), preventive health, laws, health 


\section{Manteniendo el Esquema de Aseguranzas Nacionales de Salud a través de la Legislación y de Estrategias Preventivas de Salud}

Samuel Adu-Gyamfi

Kwame Nkrumah University

of Science and Technology

\author{
Aminou Dramani \\ Kwame Nkrumah University \\ of Science and Technology
}

\section{Resumen}

Este artículo se centra en primer lugar en literatura secundaria para subrayar algunos de los temas clave que han afectado la efectividad y la eficiencia de la Seguridad Nacional de Salud de Ghana. El artículo propone la necesidad de utilizar la legislación y estrategias de salud preventivas adicionales para rebajar o reducir la presión que se cierne sobre la Autoridad de la Seguridad Nacional de Salud. Finalmente, postula que los miembros de una comunidad, sus instituciones de salud e instituciones de para-salud que aseguran la seguridad pública, la protección medioambiental, y la sanidad entre otras cosas; estén orientados a reducir las enfermedades, accidentes y males. Esto podrá asegurar una fuerza de trabajo y una población saludable proclive a aumentar la productividad y reducir la cantidad de enfermedades con sus males y costes estatales asociados, especialmente en países donde se practica la seguridad social.

Palabras clave: Aseguranza Nacional de Salud (ANS), salud preventiva, leyes, salud 


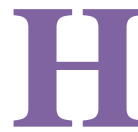

ealth as defined by the World Health Organization is a state of complete physical mental and social well-being and not merely the absence of disease or infirmity (WHO, 1948). Prepayments and risk pooling through social health insurance has been advocated by international development organizations. Social health insurance is seen as a mechanism that helps mobilize resources for health, pool risk, and provide more access to health care services for the poor. Hence Ghana implemented the National Health Insurance Scheme (NHIS) to help promote access to health care services for Ghanaians (Saltman, Busse \& Figueras, 2004).

Writing in 1987, Epp argued that health ceases to be measured strictly in terms of illness and death. It has evolved to include what has become a state in which individuals and communities strive to achieve, maintain or regain, and not something that comes about as a result of treating and curing illnesses and injuries. It should also include basic and dynamic force in our daily lives, influenced by our circumstances, beliefs, culture including social, economic and physical environments (Epp, 1987).

Everybody at some time in life, and often on many occasions, will need some kind of medical attention and treatment. When medical care is required, ideally the patient should be able to concentrate on getting better, rather than wondering whether he/she could pay for all the bills. In some countries, such as the United Kingdom or Canada, health care coverage is provided by the state and is seen as every citizen's right -it is classed along with public education, the police, fire-fighters, street lighting, and public road networks, as a part of a public service for the nation.

In other countries, such as the USA, health insurance coverage is seen somewhat differently -with the exception of some groups, such as elderly and/or disabled people, veterans and some others, it is the individual's responsibility to be insured. More recently, the Obama Administration has introduced laws making it mandatory for everybody to have health insurance, and there are penalties for those who fail to have a policy of some kind. Significantly, Stuckler and Basu (2013) have argued that when governments invest more in social welfare programs - housing support, unemployment programs, old-age pensions, and healthcare- 
health improves and this is not merely a correlation, but a cause- and- effect relationship seen across the world (Stuckler \& Basu, 2013).

Community-based health insurance and mandatory health insurance for for either the entire population or a segment of it seem to be gaining ground ground in sub-Saharan Africa. Ghana's scheme is one of very few attempts attempts by a sub-Saharan African country to implement a national-level, universal health insurance program (Kirigia, Preker, Carrin \& Mwikisa, 2006). Healthcare financing through social health insurance or tax-funded schemes has become a very important tool in achieving universal financial protection for healthcare in most developing countries such as Ghana. Contributions to these schemes are usually based on one's means, and as such these systems provide relatively fairer means of financing healthcare, which is particularly good for the poor (Gajate-Garrido \& Owusua, 2013).

The National Health Insurance Authority (NHIA) was established under the National Health Insurance Act 2003, Act 650, (now replaced by a new law, Act 852) as a body corporate, with perpetual succession, an Official Seal, that may sue and be sued in its own name. The NHIA was commissioned "to secure the implementation of a national health insurance policy that ensures access to basic healthcare services to all residents" (National Health Insurance Act, Act 650, 2003). The object of the Authority is to secure the implementation of a national health insurance policy that ensures access to basic healthcare services to all residents. The Authority, among others ensure equity in health care coverage, access by the poor to healthcare services, protection of the poor and vulnerable against financial risk, manage the National Health Insurance Fund, receive, process and pay claims for services rendered by healthcare providers, undertake programmes that further the sustainability of the National Health Insurance Scheme (NHIS) and generally oversees and reports on NHIS operations. AduGyamfi, Brenya and Amoah (2015) argue that people access the facilities rampantly even when they have gone for treatment and it is not time for them to go for review. They also allude to the multiple inflation of cost by health or medical facilities. Dalinjong and Laar (2012) argue that high attendance and perceived service abuse by the insured had led to an increased workload for providers. Providers experience long working hours with little or no break times. However, providers were not motivated enough 
by the NHIS and government to compensate for the heavy workload experienced (Dalinjong and Laar, 2012). This to an extent increases the burden on the National Health Insurance Authority.

The importance of Social Health Insurance (SHI) has been by different studies, the argument that Social Health Insurance alone is ultimate in dealing with the challenge of healthcare has been directly and by inference contested. Writing on social health insurance for developing nations, Shaw (2007) argued that SHI should not be seen as a magic bullet that will solve all the woes of healthcare financing and provision in developing countries including Ghana. This suggests that other elements or ingredients are essential in spicing the "financing Pudding" offered by SHI.

Although some studies have been done on the NHIS, none of them has focused on how preventive healthcare legislation can help ease the heavy financial demand which is collapsing the scheme. The major cause for concern in Ghana's quest for answers about health delivery in the country is not even the much talked about administrative, managerial, training, exploitative and profiteering schemes of service providers to the National Health Insurance scheme often at the blind side of patients and other areas of the sector. Rather, this paper seeks to focus on the preventive care provisions with some comparative analysis or general outlook from the globe. Of great importance to the discourse is for us to find out the importance of public health laws on communicable diseases, non-communicable diseases, the position of the World Health Organization on communicable and non-communicable diseases as well as the position of Ghana Health Service on Public Health Laws.

The paper is divided into three sections. Following this introduction, background information on the NHIS is presented, including a brief review of previous studies of this scheme as well as evidence that the scheme is in financial crisis. The final section explains why preventive healthcare law and strategy is necessary and recommends what should be included in such a law. 


\section{Ghana's National Health Insurance Scheme}

Health care financing in Ghana began with a tax sponsored system that provided free public health care services to all after independence. As this system gradually became financially unmanageable especially with the economic challenges in the 1970s, low user fees were established for hospital services to deal with unnecessary access, and to also locally recover some costs and generate provider performance incentives. Continued regressions in government spending on health through the 1970s and 1980s led to shortages of medicines and supplies and worsening quality of care. Following adoption of structural adjustment reforms in 1983, the Rawlings administration elevated and extended user fees for public health care services in a system that became known as "cash and carry." The user fee system improved operating revenues for some facilities, but it was poorly regulated, inconsistently implemented, and found to have worsened access to care for the poor (Blanchet, Fink \& Osei-Akoto, 2012).

Starting from the early 1990s, Ghana began to seek other ways of financing health care, including NGO introduced community-based health insurance schemes (CBHIS). While popular among members and international donors at the time, the schemes were only targeted to specific areas, failed to address key social insurance issues, and were not sustained by general government revenue to allow them to satisfy for the poor. Most prominently, with CBHIS covering only about $1 \%$ of the population with limited benefit packages, the system of user fees continued the principal means of paying for health care. The highly unpopular out of pocket cost for medical care also referred to in Ghana as "cash and carry" system became an outstanding political issue and the main opposition party, the New Patriotic Party (NPP), called for its abolishment in its manifestos and campaign promises. This might have helped the NPP win the 2000 presidential and parliamentary elections (Blanchet, Fink \& Osei-Akoto, 2012).

Ghana's National Health Insurance Scheme (NHIS) was introduced in 2003 to replace the fee for service system. It was created by the National Health Insurance Act of August 2003. The NHIS is financed from four main sources: a value-added tax on goods and services, an earmarked portion of social security taxes from formal sector workers, individual premiums, and 
miscellaneous other funds from investment returns, Parliament, or donors. The $2.5 \%$ tax on goods and services, called the National Health Insurance Levy (NHIL), is by far the largest source, comprising about $70 \%$ of revenues. Social security taxes account for an additional $23 \%$, premiums for about 5\%, and other funds for the remaining 2\% (Yankah, 2009; Adu-Gyamfi, 2015).

The NHIS (including all DMHISs) has a single benefit package that is set by Legislative Instrument 1809 and described by the NHIA as covering "95\% of disease conditions" that afflict Ghanaians (National Health Insurance Regulations, LI 1809, 2004). The NHIS covers outpatient services, including diagnostic testing and operations such as hernia repair; most in-patient services, including specialist care, most surgeries, and hospital accommodation (general ward); oral health treatments; all maternity care services, including Caesarean deliveries; emergency care; and, finally, all drugs on the centrally-established NHIA Medicines List.

Finally, one of the objectives of the NHIS is to be able to provide funds to health care providers in bulk for planning purposes to ensure efficient and effective delivery of healthcare service, thus, solving the problem of inability of patients to pay for the cost of healthcare (Akosua Akortsu \& Aseweh, 2011).

\section{The Position of the Literature}

If properly managed, the NHIS comes along with increased access to health care and general improvement in health of the people (Adu-Gyamfi et al., 2015). According to Dalinjong and Laar NHIS has made access to health care services very easy. This was due to the fact that one is not required to pay for services at the point of consumption (Dalinjong \& Laar, 2012). By the end of 2011, the total number of accredited health facilities was 3,344, in contrast to 1,672 in 2008. Outpatient utilization of healthcare services increased more than fortyfold, from 0.6 million in 2005 and 16.9 million in 2010 to 25.5 million in 2011. Also, Dalinjong and Laar have confirmed the utilization of health care services have increased under the NHIS. For instance, both baseline and end line studies on the NHIS saw an increase in 
utilization of health care services from $37 \%$ in 2004 to $70 \%$ in 2008 in Ghana. Similarly, the Ministry of Health (Ghana) reported that the use of outpatient and inpatient services under the NHIS almost doubled between 2005 and September 2007 (Dalinjong \& Laar, 2012). Finally, inpatient utilization increased more than thirtyfold from 28,906 in 2005 to 973,524 in 2009, and then it rose further to 1,451,596 in 2011 (NHIA, 2011). According to Asuming (2013) the insurance coverage has led to reduced out-of-pocket payments among individuals with prior positive expenses and also to improved health outcomes (fewer days of illness suffered). According to the 2008 Citizens' Assessment (NDPC, 2009), being an NHIS cardholder improves the chances of seeing high-quality health professionals (doctors and medical assistants versus consult drugstores and traditional providers). Similarly, being registered in the DMHIS increases the probability of seeking higher quality maternal healthcare as well as the likelihood that parents take their children to health facilities more often for both curative and preventive care (Gajate-Garrido \& Ahiadeke, 2013). NHIS members have a higher probability of obtaining prescriptions, visiting clinics, and seeking formal healthcare when sick (Blanchet, Fink \& Osei-Akoto, 2012). The 2008 Citizens' Assessment (NDPC, 2009) indicates that the number of days of school or work lost due to illness is highest among those who have not registered (4.8 days) compared with days lost by the insured population (3.6 days). Finally, pregnant women who participate in the scheme enjoy reduced incidence of birth complications and are more likely to receive prenatal care, to deliver at a hospital, and to be attended by a trained health professional during birth (Mensah, Oppong \& Schmidt, 2009).

\section{Financial Challenges of the NHIS and Implications}

Unfortunately, the NHIS is bedevilled with challenges including the inability to pay claims for services rendered by healthcare providers. Gajate-Garrido and Owusua (2013) identified delayed reimbursement of claims as an issue in several regions, especially in the Ashanti, Brong Ahafo, and Western regions. Akosua Akortsu and Patience Aseweh also identified that the NHIS is not a reliable source of financing, although the policy is a good one. In their research most of the respondents lamented that there are delays in the 
payment of reimbursements. They explained that reimbursements from the use of the scheme are supposed to take a maximum of four weeks. However, payments for services rendered to subscribers could take as long as twelve months. It was found that the delays tend to affect the ability of the Hospital to pay suppliers of drugs and also impede the smooth running of the Hospital (Akosua Akortsu \& Aseweh, 2011). The Executive Director of Health Insurance Service Providers Association of Ghana (HISPAG), Frank Richard Torblue, disclosed that the NHIA owed the service providers GHф213 million which is for a four-month claim out of the seven months (Daily Guide, 2016). The Chairman of the Public Accounts Committee (PAC) of Parliament asked the Health Minister to lobby cabinet to release enough money for the running of the National Health Insurance Scheme (NHIS) because the scheme is choked with huge debt which is crippling its operations. The minister admitted that the NHIA owes several health service providers accredited to the scheme in arrears of between six and eight months, and that the funding sources cannot match the growing number of people getting registered into the health insurance scheme (Daily Guide, 2016).

Anecdotal evidence suggests that there exists over-utilization and health shopping among health facilities by the insured, an evidence of moral hazard and a negative effect on the quality of healthcare being delivered as a result of the increasing utilization. The perceived low quality of service received from healthcare providers were attributed to unavailability of drugs and long waiting times. The seemingly unavailability of drugs was in part attributed to delays in submission of claims by health facilities and reimbursement by the scheme, which put financial burden on the facilities considering the fact that most of them now earn more than $80 \%$ of their revenue from insurance (Gobah \& Zhang, 2011).

The non-payment of claims by the NHIA has led to card bearing members of the scheme being denied services as the service providers refuse to render any more service until their money is refunded to them. Such a situation affects the health seeking behaviour of the population. It comes with negative tendencies on the health of the entire nation resulting in low productivity, high cost of living and emergence of social 
and economic delinquencies. It worsens access to basic healthcare for the poor. It may also mean reintroduction of charging of fees. There is overwhelming evidence that suggests that user fees constitute a strong barrier to the utilization of health care services, as well as preventing adherence to long term treatment among poor and vulnerable groups (James, (James, Hanson, McPake, Balabanova, Gwatkin, Hopwood \& Preker, 2006; Palmer, 2004).

The delay in payment had made providers resort to the issuance of prescription forms for insured clients to buy drugs out of the facilities. Another consequence of the delay in reimbursement was the fact that it had made some providers prefer clients who would make Out of Pocket Payments (OOP) for services to those with the NHIS cards. These OOP payments from the uninsured assist providers to run the facilities while they wait for the main payments from the NHIS. In addition, providers were handicapped in the payment of their casual employees. For example, cleaners and security men whose names were not on government's payroll are usually paid from internally generated funds mobilized by the facilities (Dalinjong \& Laar, 2012).

\section{Discussion}

This section focuses on the essence of the law in ensuring prevention of diseases and also to reduce the fiscal burden diseases impose on health care financing. The question asked is why is law important in the sustenance of Ghana's health insurance? There are other important themes that are discussed to supplement the issues on law.

\section{Why is Law Important}

Of all the professions with which health workers must deal with, law is undoubtedly the most pervasive. Law does not only constitute the structural framework of the whole of our organized society including our multitude of governments, but it provides those rules or norms of conduct to which society expects adherence and the means of compelling adherence when that is necessary. Every governmental agency is created and its authority defined 
by law, and every administrative regulation and every expenditure of public funds must be authorized by law. Practitioners are licensed and institutions chartered and their authority fixed by law. Health agencies, public and private, and practicing members of the health professions, because of the critical importance to the public of what they do, are held to a high measure of accountability, of which the law is and must be the final arbiter (Willcox, 1964).

The law is in some sense the master and in some sense the servant of the health professions, whether in the traditional realms of public health or in the private practice of these professions. If it is the master in defining what may legally be done and how, it should be the servant in its readiness to adapt, at the behest of other disciplines, to the changing needs of the times. If it is the servant in enforcing those rules of conduct which the health professions have found necessary to the protection of the public, it is the master in setting bounds beyond which the rules may not impinge on the rights of individuals. We live in an age when man is challenged as never before by the need to adjust his social institutions including, conspicuously, the law to keep pace with his ever broadening mastery over nature (Willcox, 1964).

The majority of conditions leading to out-patient attendance at clinics in Ghana are malaria, diarrhoea, upper respiratory tract infection, skin disease, accidents, hypertension, eye infection, pregnancy-related conditions, among others. In fact, the poor environmental conditions in which Ghanaians live, work and go to school has a major impact on their wellbeing. The poor air, water and soil quality in the country is mainly due to improper disposal of waste, emission of dangerous gases from industries and vehicles, and smoke from burning of waste and bush fires. Despite this situation, the measures for controlling these problems have not been effective. Access to potable water, for instance, is a problem. Less than half of the population in the country has access to potable water (NHP, 2007) leaving the rest to obtain water from streams and rivers, which are often contaminated with organic and inorganic substances from household and industrial pollutants. Even where portable water is available, beliefs and social misconceptions leave such a facility unused. 
Most of these diseases are preventable if appropriate legal, environmental and lifestyle measures are taken. Over $90 \%$ of these diseases and conditions could easily be prevented (NHP, 2007). However, instead of developing and promoting preventive health lifestyles through good nutrition, regular physical exercise, recreation, rest and personal hygiene, safe food, housing and roads to the benefit of its people, health programmes and projects in the country have focused on curative care (Adu-Gyamfi et al., 2013). The over concentration on curative health largely contributes to the large number of card bearing members reporting at the hospitals and other health facilities daily. This has direct financial implication to the National Health Insurance Scheme (NHIS) as a social intervention programme that seeks to increase access to basic quality health care. Poor service delivery by health care providers under the NHIS is an act that defeats the purpose for which the scheme was established.

While this paper does not intend to overlook the critical nature of the other sources of challenges facing the scheme, it recommends the promulgation of laws or amendment of existing ones to promote preventive healthcare. Such laws may promote good health among the populace and thereby reduce the volume of claims from the scheme. New laws (or amendments) to enhance the work of sanitation inspectors (commonly known as 'saman saman or tankase fo') can, at least, help to ensure clean environment in our immediate surroundings and thereby improve personal hygiene. Health and Sanitation are vital components of human health and development. Improved sanitation according to medical scientists reduces diseases such as cholera, diarrhoea, worm infestation, pneumonia, malaria and typhoid, among others and death in millions of people.

Also, all radio and television stations should be mandated to design and promote preventive health awareness campaign programmes. Such programmes could take the form of drama, documentary or even advertisements. This could come as part of their corporate social responsibility. Remember, radio gets results. Significantly, the question is if people do not get sick would they go to hospitals in the first instance? By less people going to the hospitals financial burden on the NHIS will reduce and that in essence has the tendency or the proclivity to ensure a smooth running of the NHIS. 
Commenting on public health law and non-communicable diseases, Tanaka et al. (2014) drew our attention to the background of diseases and public health. Law, imposition of statutory duty on a range bodies to reduce health inequalities, legislation to bring about a renewed focus on the prevention of ill health as well as the legislation to community action around health protection and improvement. She argued that by 2008 , nearly two-thirds of all deaths- 36 million were caused by non-communicable diseases, cancers, diabetes, and chronic lung diseases. With the increasing number of global deaths arising out of non-communicable diseases, social insurance would have to focus on this. If that is the case, there should be modalities or laws to ensure effective, individual, organisational or institutional and proper community behaviour to reduce the number of people who suffer from these diseases and would have to depend on social insurance. Tanaka et al. argues that economic burden of NCDs is sizeable, with a 2011 projection of cost on world economy amounting to 47 trillion dollars over the next two decades which is approximately seventy-five percent of the 2010 global Gross Domestic product (GDP).

As put out by the WHO "Investing in prevention and better control of this broad group of disorders will reduce premature death and preventable morbidity and disability, improve the quality of life and wellbeing of people and societies, and help reduce the growing health inequalities they cause" (WHO, 2011). World Health Organisation 2011 Strategies for NCD Interventions include:

- Protecting people from tobacco smoke and banning smoking in public places.

- Enforcing bans on tobacco advertising, promoting and sponsorship.

- Raising taxes on tobacco

- Restricting access to retailed alcohol

- Enforcing bans on alcohol advertising

- Raising taxes on alcohol

- Reducing salt intake and salt content of food

- Replacing trans- fats in food with polyunsaturated fat 
- Promoting public awareness about diet and physical activity, including through mass media.

Globally, Tanaka et al. (2014) has argued that between 1972 and 2006, as 2006 , as a result of a policy focused on healthy diet, exercise and the reduction of smoking, the world witnessed $85 \%$ decrease in annual mortality mortality rate from coronary heart disease. Also by 2013, in New York, a five-year old health Department regulation banning trans- fats has reduced consumption of trans fats among fast-food customers from about 3 grams to 0.5 grams per purchase-which shows that local health regulations can significantly influence public consumption.

\section{The Importance of Public Health Law}

In 2007 the Nuffield Council on Bioethics presented a vision on the stewardship role of the state. They emphasized that governments have a duty to look after important needs of people individually and collectively. It was anticipated that goals of public health programmes would encompass reduction of risk, environmental protections, and protections for vulnerable populations, health promotions, enabling the populations to make healthy choices, access to medical services and a reduction of health inequalities.

Public health law is defined among others as "the study of the legal powers and duties of the state to assure the conditions for people to be healthy (example to identify, prevent and ameliorate risks to health in the population) and the limitations on the power of the state to constrain the autonomy, privacy, liberty or other legally protected interests of individuals for protection or promotion of community health". Hoke and Swinburne also defined Public health law as a field that focuses legal practice, scholarship and advocacy on issues involving the government's legal authorities and duties "to ensure the conditions for people to be healthy, and how to balance these authorities and duties with "individual rights to autonomy, privacy, liberty, property and other legally protected interests. The scope of public health law is broad. Public health law issues range from narrow questions of legal interpretation to complex matters involving public health policy, social justice and ethics (Hoke \& Swinburne, n.d.). 
Comparatively, in the United States, Federal and state laws prohibiting the production, sale, use or possession of synthetic drugs are an important element in the public health response but law enforcement officials face significant hurdles in pursuing criminal charges against those who sell synthetic drugs. Essentially, other scholars like Mariner (2009), Magnusson (2007), and Burris, Kawachi and Sarat (2002) argue among others that public health laws should focus on determining or serving as a mechanism for the health effects of social and physical environments. Callahan and Jennings (2002) have also argued toward this end that as the concern of health policymakers turn toward health outcomes, cost-effectiveness, and preventive measures throughout the life cycle (primary, secondary, and tertiary prevention), the field of public health is gaining increased public and legislative attention. They further argue among other things that Public health, especially the public health professional in many matters has the legal power especially the police power of the state behind it. As a result of that it can through use of law, compel citizens to behave in an approved healthy way especially through compulsory immunization of their children, restriction on smoking in public places, or by quarantining them to stop the spread of infectious disease (Callahan \& Jennings, 2002).

However, researching on international law and global health, Fidler (1999) concluded by warning that neither law nor global health jurisprudence provides a panacea for the public health problems facing the planet. He argues among other things that law is ultimately an instrument in human affairs, not an end in itself and legal energy alone is not enough to establish footholds on the mountains of problems confronting humanity. This notwithstanding, Hodge (1998) argued that "there is perhaps no facet of governmental regulation more important to the public welfare than the maintenance of public health. The role of law is vital to the accomplishment of public health objectives. The field of public health owes its existence in large part to the role of government and the laws it enacts to control the factors which contribute to a healthier society. As a result, the field of public health law is coextensive with the dynamic field of public health: the goals of the latter necessarily become, at least in part, the objectives of the former". In Africa and Ghana in 
particular, the challenge of implementation of some of existing public health regulations stem from the lack of preparedness on the implementers of the law and the recipients to change from ingrained negative attitudes that public health laws are anticipated to engineer in the society to bring about good health and well-being.

District Assemblies must create Sanitation Section. Where such sections already exist, they must be strengthened and made responsible for the maintenance of public health. The core duties of the section are primarily to ensure public cleansing, proper waste management, effective pest and disease control, supervision of food hygiene and undertaking fumigation services. This in essence would reduce the disease burden on the population which means that there would be little or minimal spending from the insurance kitty on health. Again, referring to colonial records on Ghana show those sanitary bye-laws prevented the spread of diseases like virulent diarrhoea and bubonic plague among others (Adu-Gyamfi, Adjei \& OwusuAnsah, 2013).

The implementation of existing laws on sanitation, city and urban planning, the ban on marijuana usage, the restrictions on the use of tobacco among others do not only have the tendency and proclivity to ensure public safety and well-being but also reduces the financial burden on healthcare financing. As already argued by Tanaka et al. (2014), law can be used to advance public health in a number of different ways. For example, for emphasis our attention is drawn to a 2011 report from the WHO Regional Office for Europe which sets out four major roles. They include the following: defining the objectives of public health and influencing its policy agenda; authorising and limiting public health action with respect to protection of individual rights, as appropriate; serving as a tool for prevention; and facilitating the planning and coordination of governmental and non-governmental health activities. We could also infer from same literature that there are essential areas to look out for in legislating to improve upon the health of society which also has the potential to reduce the pressure on National Health Insurance with Ghana not an exception. The areas include extending the requirement to use Health Impact Assessments; imposing a statutory duty on a range of bodies to reduce health inequalities; legislation to bring about a renewed focus on prevention of ill health; and 
legislation to strengthen community action around health protection and health improvement (Tanaka et al., 2014).

Comparatively, Epp (1987) argued concerning the adult population in Canada that with regard to adults, the use of preventive measures could to a future $50 \%$ reduction in the incidence of lung cancer and heart Concerning this, we include legislations that ensure that institutions concerned with health promotion and preventive healthcare are able continuously and persistently ensure that the population especially the adult population is able to act in a way or pursue causes that would ensure good health and well-being.

\section{Preventive Healthcare}

Again, Epp (1987) argued among other things that prevention involves identifying the factors which cause a condition and then reducing or eliminating them. He argued that within the nineteenth century, through the efforts of public health, the practice of prevention gained wider acceptance across the globe. Immunization and the chlorination of drinking water were prime examples of measures introduced to prevent and reduce the incidence of infectious disease.

Within the twentieth century, preventive efforts were extended into areas like individual lifestyle and behaviour. Comparatively, Epp (1987) argued that in Canada, the realization that smoking, alcohol consumption and high-fat diets were contributing to lung cancer, cirrhosis of the liver, cardiovascular disease and motor vehicle accidents, led the country to turn their attention to reducing risk behaviour and tried to change people's lifestyles. Closely linked to this is the element of health promotion. Epp (1987) refers to the WHO that "health promotion is the process of enabling people to increase control over, and to improve, their health". It "represents a mediating strategy between people and their environments, synthesizing personal choice and social responsibility in health to create a healthier future" (Epp, 1987). This health promotion should not be restricted only to the making of pamphlets and posters about health but it should include health education, training, research, legislation, policy coordination and community development (Epp, 1987). It is essential that 
in any country including Ghana where such strategies are deployed, it should be able to reduce disease burden on the population in the country and further lessen the pressure it would put on the existing social or health insurance because of over patronage or hospital attendance due to ill health. The public health profession itself should have a lot of political power and governmental support including the necessary ethical considerations to allow for effective prosecution of the health agenda as expressed by Callahan and Jennings (2002). They argued that "Public health also has the distinction, along with a few others — such as city management, public administration, and law enforcement - of being a profession in which many practitioners are government employees and officials. It has an obligation both toward government, which controls it, and toward the public that it serves" (Callahan \& Jennings, 2002).

\section{Conclusion}

Health delivery in Ghana is faced with such a complexity of problems that instead of improving and becoming sophisticated, it rather deteriorates by the day. There are so many thousands of patients who throng our hospitals, clinics, polyclinics and sometimes health centres everyday seeking health care. The numbers are overwhelming to an extent that it has made these facilities look like hopeless refugee holding centres. In all such cases, it is the poor and the vulnerable who are worst affected. To avoid any humanitarian disaster and ensure that Ghanaians are healthy, happy and hearty to work for the attainment of the goals of the country, drastic measures must be taken and swiftly. Preventive health legislation with effective enforcement mechanisms is the solution.

From what the literature has put out; whether on the question of public health law on communicable diseases, the position of the WHO on health laws, as well as the position of the Ghana Health Service suggest that prevention is better than cure. To a larger extent, the people of a community, their institution, that is health institutions and Para-health institutions that ensure public safety, environmental protection, and sanitation among others are enjoined to reduce the occurrence of disease, injury or harm. This would ensure a healthy work force and healthy population that has the tendency or 
proclivity to increase productivity and reduce disease burden with its associated harm and cost on state, especially where social insurance is practiced.

Gobah and Liang (2011) have reported that "there exists overand health shopping among health facilities by the insured, an evidence moral hazard and a negative effect on the quality of healthcare being delivered as a result of the increasing utilization. The perceived low quality of service received from healthcare providers were attributed to unavailability of drugs and long waiting times." This amply suggests among others that there is the need to look at preventive health care to deal with the frequent utilization of hospitals or health centres to reduce disease burden on the population which will reduce the cost or expenditure that burdens the National Health Insurance Authority. It is justifiable to note however, that it does not make economic sense to have oversubscription of health insurance but the funds do not complement the expenditure due to overutilization of the health facilities or hospitals. Legislation or laws that seek to at least deal with the conduct of members of society with regard to their own health and well-being would produce a healthy population that would visit the hospital fewer times in a given year or more. This in essence would add to the success of the health insurance.

It can therefore be surmised that the National Health Insurance in Ghana continues to be plagued by oversubscription and utilization of health centres. There are moral and legal arguments that have been raised to direct both patients and management of health facilities to help reduce the cost or expenditure in financing the health and well-being of individuals. However, in this paper we have argued that effective public health laws and other legislations that prevent the use of harmful drugs/herbs among others would improve the health and well-being of the population and further lessen hospital visits and the claims that are made by the medical facilities. This has the proclivity to reduce the pressure on the National Health Insurance Authority and ensure the sustenance of the National Health Insurance Scheme. It is envisaged that in this instance the centrality of law for the work of public health should 
bring uncommon visibility to its actions and an uncommon need for public accountability (Callahan \& Jennings, 2002).

\section{References}

Adu-Gyamfi, S., Brenya, E., \& Amoah, A. (2015). National Health Insurance Scheme of Ejisu-Juabeng and Matters Arising. International Journal of Social Science Studies, 3(5), 40-60. doi: 10.11114/ijsss.v3i5.962

Adu-Gyamfi, S., Brenya, E., \& Adjei, G.N. (2015). National Health Insurance and Free Maternal Healthcare in Ghana: Reponses from Women and Health Workers in Akropong. Modern Research Studies: An International Journal of Humanities and Social Sciences, 2(4), 696-737.

Adu-Gyamfi, S., Osei-Wusu Adjei, P., \& Owusu-Ansah, D. (2013).

Preventive Healthcare Strategies Among the Asante People of the Early Twentieth Century Gold Coast: A Historical Narrative and Lessons for the Present Sanitation Challenge in Kumasi. Journal of Studies in Social Sciences, 5(2), 214-238.

Akosua Akortsu, M., \& Aseweh Abor, P. (2011). Financing Public healthcare institutions in Ghana. Journal of Health Organization and Management, 25(2), 128-141. doi: 10.1108/14777261111134383

Asuming, P.O. (2013). Getting the Poor to Enroll in Health Insurance, and its effects on their health: Evidence from a Field Experiment in Ghana. Job Market Paper - Columbia University.

Blanchet, N.J., Fink, G., \& Osei-Akoto, I. (2012). The Effect of Ghana's National Health Insurance Scheme on Healthcare Utilisation. Ghana Medical Journal, 46(2), 76-85.

Burris, S., Kawachi, I., \& Sarat, A. (2002). Integrating Law and Social Epidemiology. Journal of Law Medicine and Ethics, 30(4), 510-521. doi: 10.1111/j.1748-720X.2002.tb00422.x

Callahan, D., \& Jennings, B. (2002). Ethics and Public Health: Forging a Strong Relationship. American Journal of Public Health, 92(2), 169176. doi: 10.2105/AJPH.92.2.169 
Daily Guide (2016, January 26). Save NHIS From Collapse - PAC Tells Health Minister. Daily Guide. Retrieved from: https://www.modernghana.com

Dalinjong, P.A., \& Laar, A.S. (2012). The national health insurance scheme: perceptions and experiences of health care providers and clients in two districts of Ghana. Health Economics Review, 2(1), 2-13. doi: 10.1186/2191-1991-2-13

Epp, J. (1987). Achieving Health for all: A framework for Health Promotion. Health Promotion, 1(4), 419-428.

Fidler, D.P. (1999). International law and infectious diseases. Oxford: Oxford University Press.

Gajate-Garrido, G., \& Owusua, R. (2013). The National Health Insurance Scheme in Ghana: Implementation Challenges and Proposed Solutions. IFPRI Discussion Paper 01309.

Gajate-Garrido, G., \& Ahiadeke, C. (2013). The Effect of Parents' Insurance Enrolment on Healthcare Utilization: Evidence from Ghana. SSRN. doi: 10.2139/ssrn.2158824

Galbraith-Emami, S. (2013). Public Health Law and Non-Communicable Diseases. London: UK Health Forum.

Galbraith-Emami, S., \& Lobstein, T. (2013). The impact of initiatives to limit the advertising of food and beverage products to children: A systematic review. Obesity Reviews, 14(12), 960-974. doi: 10.1111/obr.12060

Gobah, F.K., \& Zhang, L. (2011). The National Health Insurance Scheme in Ghana: Prospects and Challenges: A Cross-Sectional Evidence. Global Journal of Health Science, 3(2), 90-101. doi: 10.5539/gjhs.v3n2p90

Hodge, J.G. (1998). Role of New Federalism and Public Health Law. The Journal of Law \& Health, 12(2), 309-357.

Hoke, K., \& Swinburne, R.M. (n.d.). What is Public Health Law? Retrieved from The American Public Health Association website: https://www.apha.org/

James, C.D., Hanson, K., McPake, B., Balabanova, D., Gwatkin, D., Hopwood, I., Kirunga, C., Knippenberg, R., Meessen, B., Morris, S.S., Preker, A., Souteyr, Y., Tibouti, A., Villeneuve, P., \& Xu, K. 
(2006). To retain or remove user fees? Applied Health Economics and Health Policy, 5(3), 137-153. doi: 10.2165/00148365-20060503000001

Kirigia, J.M., Preker, A., Carrin, G., Mwikisa, C., \& Diarra-Nama, A.J. (2006). An overview of health financing patterns and the way forward in the WHO African Region. East African Medical Journal, 83(9 Suppl), S1-S28. doi: 10.4314/eamj.v83i9.9492

Magnusson, R.S. (2009). Rethinking Global Health Challenges: Towards a Global Compact for Reducing the Burden of Chronic Disease. Public Health, 123(3), 265-274. doi: 10.1016/j.puhe.2008.12.023

Mariner, W.K. (2009). Toward an Architecture of Health Law. American Journal of Law and Medicine, 35(1), 67-87. doi: 10.1177/009885880903500102

Mensah, J., Oppong, J.R., \& Schmidt, C.M. (2009). Ghana's National Health Insurance Scheme in the Context of the Health MDGs: An Empirical Evaluation Using Propensity Score Matching. Ruhr Economic Papers, 157, 1-20. doi: 10.2139/ssrn. 1532169

Ministry of Health (2007). National Health policy: Creating Wealth through Health. Accra: Ministry of Health.

National Development Planning Commission (NDPC) (2009). 2008 Citizens. Assessment of the National Health Insurance Scheme. Accra: NDPC.

National Health Insurance Act, Act 650. 2003.

National Health Insurance Authority (NHIA) (2009). Annual Report. Accra: NHIA.

National Health Insurance Authority (NHIA) (2011). Annual Report. Accra: NHIA.

National Health Insurance Regulations, LI 1809. 2004.

National Health Policy (NHP) (2007). Ghana National Health Policy:

Creating Wealth Through Health. Accra: Ministry of Health.

Palmer, N., Mueller, D.H., Gilson, L., Mills, A., \& Haines, A. (2004). Health financing to promote access in low income settings-how much do we know? Lancet, 364(9442), 1365-1370. doi: 10.1016/S0140-6736(04)17195-X 
Saltman, R., Busse, R., \& Figueras, J. (2004). 17. Social health insurance systems in Western Europe. European Observatory on Health Systems and Policies Series.

Shaw, R.P. (2007). Social health insurance for developing nations. WBI Development Studies. Washington, DC: World Bank.

Stuckler, D., \& Basu, S. (2013). The body economic: why austerity kills. New York: Basic Books.

Tanaka, S., Hawkes, S., Pegram, T., \& Buse, K. (2014). Non-communicable Diseases: Global epidemics; global determinants; global solutions? Towards a healthy role for transnational food, beverage and alcohol industries in the global governance of noncommunicable disease risk. London: London's Global University.

World Health Organization (WHO) (1948). Definition of Health. WHO Constitution. Geneve: World Health Organization.

World Health Organization (WHO) (2011). Scaling up action against noncommunicable diseases: how much will it cost? Geneve: World Health Organization.

Willcox, A.W. (1964). The Role of Law in Public Health. Public Health Report, 79(8), 647-653.

Yankah, B. (2009). Financial sustainability of NHIS based on recent financial assessment of the scheme. Health Summit, November 16-20.

Samuel Adu-Gyamfi is Lecturer at the Department of History and Political Sciences at the Kwame Nkrumah University of Science and Technology, Ghana

Aminu Dramani is Lecturer at the Department of History and Political Sciences at the Kwame Nkrumah University of Science and Technology, Ghana

Contact address: History and Political Studies Department, Faculty of Social Sciences, Kwame Nkrumah University of Sciences and Technology, PMB, University Post Office, Kumasi, Ghana. Email: mcgyamfi@yahoo.com 

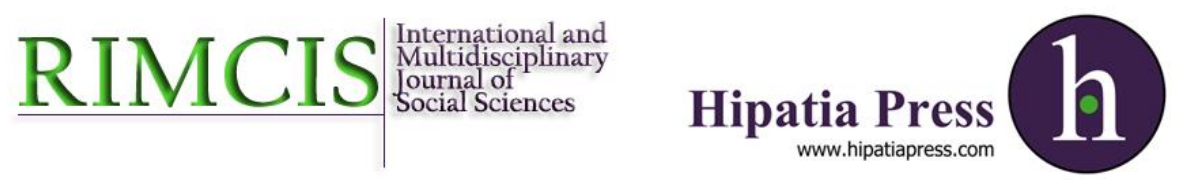

Instructions for authors, subscriptions and further details:

\section{http://rimcis.hipatiapress.com}

\section{Identifying the Relevance of Research Goals through Collecting Citizens' Voices on Social Media}

Joan Cabré Olivé ${ }^{1}$, Ramon Flecha García ${ }^{2}$, Vladia Ionescu ${ }^{1}$, Cristina Pulido $^{2}$, Teresa Sordé-Martí ${ }^{3}$

1) University Rovira i Virgili, Spain. 2) University of Barcelona, Spain.

3) Autonomous University of Barcelona, Spain

Date of publication: March $30^{\text {th }}, 2017$

Edition period: March 2017 - July 2017

To cite this article: Cabré Olivé, J., Flecha García, R., Ionescu, V., Pulido, C., \& Sordé-Martí, T. (2017). Identifying the Relevance of Research Goals through Collecting Citizens' Voices on Social Media. International and Multidisciplinary Journal of Social Sciences, 6(1), 70-102. doi:

10.17583/rimcis.2017.2652

To link this article: http://doi.org/10.17583/rimcis.2017.2652

\section{PLEASE SCROLL DOWN FOR ARTICLE}

The terms and conditions of use are related to the Open Journal System and to Creative Commons Attribution License (CC-BY). 


\section{Identifying the Relevance of Research Goals through Collecting Citizens' Voices on Social Media}

Joan Cabré-Olivé

University Rovira i Virgili

Vladia Ionescu

University Rovira $i$ Virgili

Teresa Sordé-Martí

Autonomous University of Barcelona
Ramon Flecha-García

University of Barcelona

Cristina Pulido

University of Barcelona

\section{Abstract}

Recent debates on the meaning and use of science are focused on addressing citizens' needs or concerns of society in different fields. Researchers have developed different methodologies for capturing the relevance of topics to be addressed by research in order to map them. This article proposes a new methodology for identifying the relevance of research goals through collecting citizen's voices on Twitter and Facebook combing two approaches: top down, starting with already defined research goals priorities, and bottom up, departing from the social media. The article presents the results of the application of this methodology through the research goals of Sustainable Development Goals to identify their relevance and if there are some topics not covered by them. Thus, researchers could integrate this methodology in their daily work and be more in line with the needs expressed by citizens in social media.

Keywords: social media, research, trends, citizens, voice 


\section{Identificar la Relevancia de los Objetivos de Investigación a través de las voces de la ciudadanía en las Redes Sociales}

Joan Cabré-Olivé

University Rovira i Virgili

Vladia Ionescu

University of Rovira i Virgili

Teresa Sordé-Martí

Autonomous University of

Barcelona

\author{
Ramon Flecha-García \\ University of Barcelona \\ Cristina Pulido \\ University of Barcelona
}

\section{Resumen}

Debates recientes sobre el sentido de la ciencia están centrados en cómo responder a las necesidades de las personas ciudadanas y a las preocupaciones de la sociedad en diferentes campos. Diversos equipos de investigación han desarrollado diferentes metodologías para capturar la relevancia de los temas a ser abordados como objetivos de investigación. Este artículo presenta una nueva metodología para identificar la relevancia de los objetivos de investigación a través de recoger las voces de las personas ciudadanas en Twitter y Facebook principalmente y combinando dos modelos; top-down, a través de palabras clave predefinidas extraídas de los objetivos de investigación seleccionados, y bottom-up, partiendo de los temas más recurrentes expresados a través de las redes sociales. El artículo presenta los resultados de la aplicación de esta metodología a través de la selección de los objetivos de investigación definidos en los Sustainable Development Goals identificando su relevancia, así como la identificación de temas no previstos en ellos. Los equipos de investigación pueden integrar esta metodología en su cotidianidad para valorar la relevancia de sus objetivos de estudio a partir de los resultados extraídos en las redes sociales.

Palabras clave: relevancia, redes sociales, investigación, ciudadanía, tendencias 
O ne of the key aspects discussed internationally by the scientific community is how research can be an answer to the citizens' concerns in different fields and how this knowledge can be available for any citizen in any part of world (Miyairi, 2014; Molloy, 2011; Whyte \& Pryor, 2011; Woelfle, Olliaro \& Todd, 2011). Hence, one of the current contributions that are addressing these questions are how different research areas can ensure social impact of their research, considering social improvements (Flecha, Soler-Gallart \& Sorde, 2015) as one of the criteria for evaluating this impact. For instance, some of the priorities that society is concerned about is violence against women, and one of the trends is focuses on finding ways to overcome it. One first step is to break the silence in those spaces where silence still prevails. This is the case of violence against women in Spanish Universities (Valls, Puigvert, Melgar \& Garcia-Yeste, 2016), research evidences are contributing to this aim. There is a wide list of examples of research that are addressing some of the priorities set out by society in different scientific fields with the corresponding evidences of their success. For instance, research on the improvement of soil quality reducing oil nitrous oxide emissions (Cayuela et al., 2014) is addressing one of the concerns of the farming community to maintain soil quality and reduce negative effects of the use of artificial products on the agricultural fields.

But a previous step is also how to identify the relevance of research goals in order to address them (Schulz, 2016). The scientific community has developed different methodologies for identifying this relevance (Altmann, Whichard \& Motter, 2013; Camarinha-Matos \& Afsarmanesh, 2004; Valkila \& Saari, 2013). These methods are mainly based on expert's views or documentation being useful for identifying current research trends. However, the dialogic turn in our societies (Aubert \& Soler, 2006) is a transversal fact that affects all different areas of society as well as research. This means that the inclusion of the citizens' voices could be helpful for the identification of the relevance of research goals. In fact, the participation of the citizens in an egalitarian way together with the researchers has a wide trajectory in the communicative methodology (Gómez, 2014) as well as in fields such as dialogic leadership (Redondo, 2016).

One method for including the citizens' voices in the identification of relevance of research goals is through data collection in social media. 
Citizens are currently using social media and other relevant online sources to express their opinions and interests (Wandhöfer et al., 2012). Yet it is important to consider the limitation that these interests are representative of those citizens who are using social media and online sources. Therefore, this article presents a methodology for identifying the relevance of research goals considering citizen's voices collected in social media through two approaches; one departing from the goals set out by supranational organizations such as the UN (top down) and gathering data collection in social media related to their corresponding keywords. In addition, another one that gathers the most pressing issues and concerns that are present in the social media (bottom up). To exemplify this methodology, the present article provides a comparative analysis of the results obtained through social media and other relevant online sources related to the priorities defined under the Sustainable Development Goals (SDG, hereinafter) defined by United Nations.

\section{Methodology for the Identification of the Relevance of Research Goals through Social Media}

The use of social media data as an information source for research purposes has increased over the last years in different scientific fields as well as subject matters (Ngai, Tao \& Moon, 2015; Wu, Sun \& Tan, 2013). The fact is that the number of citizens that use social media is increasing year by year. According to Statista ${ }^{2}$ there is an estimation of 2.51 billion social media users around the globe. Facebook has 1.87 billion active users monthly and Twitter has 319 million active users monthly. In this sense, content and communication shared by citizens through social media is influencing different sectors. For instance, the information is taken into account in business and marketing (Khang, Ki \& Ye, 2012) as well as for the political agenda (Bastos, Raimundo \& Travitzki, 2013; Torres-Nabel, 2015), news covered in media (Broersma \& Graham, 2013) or as a crucial means in natural disasters in order to save lives (Bruns \& Liang, 2012) among others.

Along these lines and with the aim to serve societal needs, research funded by different institutions must respond to the challenges that those institutions have designed in their priorities, which also need to be aligned to 
the citizens' needs. Hence, this methodology aims to contrast data obtained through social media with the priorities designed by the corresponding institution or researchers for identifying the major trends among the citizens' interests as well as to find out if some of the trends are not covered in these priorities. Top down and bottom up approaches are designed to obtain these results.

\section{Top Down Approach}

The top down approach consists in defining keywords extracted from the research goals designed by the corresponding institution to contrast if these goals are present in the citizen's opinion expressed in social media. Once the keywords were selected, they were converted into searchable words in social media. In the case of Twitter, this conversion of keywords implies using Hashtags. The scientific literature found that the use of Hashtags is one of the criteria to identify relevant topics in the Twitter community (Grasso \& Crisci, 2016; Small, 2011).

To provide an example, there are 17 Sustainable Development Goals defined by United Nations ${ }^{1}$ that have been converted in 30 searchable keywords on Twitter. This conversion consists in finding the most suitable hashtag for the goals defined here.

Once the list of obtained keywords is ready the following step is capturing the data on the Social Media and online sources selected. In this case, there are four sources selected considering that they are popular among citizens and are included as information sources in Almetrics. These sources are two social media (Facebook and Twitter) and two relevant online sources, Wikipedia (Internet free encyclopaedia) and YouTube (video sharing website). The contrast of information between different social media and online sources data is considered an important step in order to get a more consistent map of the information obtained (Nam, Lee \& Park, 2014).

\section{Data Collection \& Analysis}

In order to capture and treat data from Twitter and Facebook a combination of two software programmes is used: R-program and NVivo Plus. Wikipedia 
has an internal statistics tool, "Page view Statistics," and YouTube has its own search tool with a filter of view count.

Table 1.

Searchable Keywords

\begin{tabular}{ll}
\hline Sustainable Development Goal & Searchable Keyword/s \\
\hline No Poverty & \#nopoverty \\
Zero Hunger & \#zerohunger \\
Good Health and Well-being & \#wellbeing \#goodhealth \\
Quality Education & \#qualityeducation \\
Gender Equality & \#genderequality \#vaw (is a goal inside of this) \\
Clean Water and Sanitation & \#cleanwater \\
Affordable and Clean Energy & \#cleanenergy \\
Decent Work and Economic Growth & \#decentwork \#economicgrowth \\
Industry, Innovation, Infrastructure & \#industry \#innovation \#infrastructure \\
Reduced Inequalities & \#reduceinequalities \\
Sustainable Cities and Communities & \#Sustainablecities \#safecities \#inclusivecities \\
Responsible Consumption and & \#responsibleconsumption \\
Production & \#responsibleproduction \\
Climate Action & \#climateaction \#climatechange \\
Life below Water & \#oceansustainability \\
Life on Land & \#biodiversity \#combatdesertification \\
Peace, Justice and Strong Institutions & \#inclusivesocieties \#justice \#peacefulsociety \\
Partnerships for the Goals & \#globalpartnership \#UN \\
\hline
\end{tabular}

\section{Twitter}

Data collection on Twitter is developed using the searchable keywords through the Twitter-R Package installed in the R-program. This Package is connected with the public Twitter API (free) that has a limitation of recovering information published in a period of 7/9 days previous to the search done. The user can define the "N" (Number of tweets) in the Rprogram. For the present study, $\mathrm{N}$ was set at 10.000 . Thus, during the search the System can stop when 10.000 tweets are analysed or the period of 7/9 days is reached. An excel list is obtained with the tweets related to the searchable keywords. The value of the engagement determines the most used 


\section{Cabré-Olivé et al-Relevance of Research Goals on Social Media}

keyword during the period analysed. This value represents the sum of interactions of the users with the content. In the R-program this includes replies, favourites, RTs, and Total RTs.

\section{Facebook}

Data collection on Facebook is developed using the Rfacebook Package installed in the R-program. In this case, the data obtained is the number of public pages on Facebook that contain the searchable keyword in its public name. In this case the " $\mathrm{N}$ " is also defined with the value $\mathrm{N}=10.000$, but there is no time limitation. The value of the "talking about" determines if there are more or less people interacting with this page.

\section{Wikipedia}

Data collection on Wikipedia is extracted through the internal data statistics tool of Wikipedia namely "Page view Statistics". In order to analyse the presence of a keyword, it is necessary to find out if the keyword is on Wikipedia or not. If it is present, the number of page visits determines the value of presence. Moreover, another indicator is the number of languages in which the definition of this keyword is available. This tool also provides the option to select the period to be analysed, in this case, the range chosen is 30 days. Once some of keywords are introduced in the search tool one is redirected to other keywords that are synonyms and that are quoted in parenthesis. For instance, quality education is part of another general keyword that is education and results of the latter are collected.

\section{YouTube}

Data collection in YouTube is conducted using YouTube's internal search engine and applying the filter of "view counts". YouTube has many videos in its platform, YouTube does not indicate an exact number instead of this an approximation represented with this quote "About X videos". In order to extract the data, the number of the approximated videos is annotated, and the number of view counts of the five most viewed videos is added. One of 
strategies to refine results is to introduce the keywords in double quotes. Therefore, the relevance is determined by the number of view counts of the five most viewed videos for each keyword. It is noteworthy that this source is the only source where all keywords searched are present.

Results obtained by each social media and online source analysed are ranked by larger or smaller presence. The ranking is useful for analysing which keyword is most used by the citizens who are interacting in these social media or online sources allowing a map of these keywords. Finally, this allows us to have a global overview of the keywords' presence. This ranking is called Ranking of Total online interactions and is based on the sum of online interactions in the two social media selected (Twitter and Facebook) and two relevant online sources (YouTube and Wikipedia).

\section{Bottom Up Approach}

The bottom up approach consists in identifying topics emerging from those keywords most used by citizens in different social media and online sources. Once the list of topics is obtained, results should be contrasted with the priorities defined by the corresponding research institution and analyse if there are some issues that are not covered by the institution. In this case, the list of topics obtained is contrasted with the Sustainable Development Goals defined by United Nations.

\section{Data Collection \& Analysis}

There are two strategies for obtaining data collection from this approach. One of them is to analyse social media secondary literature reports that collect topics with large presence in the social media. For instance, Facebook elaborates a report of the most talked about global topics in a year. For the present article the report of 2016 is analysed ${ }^{3}$. Twitter also elaborates a list of the trending topics (TT) of the year; therefore 2016 trending topics of Twitter are analysed ${ }^{4}$. Lastly, the report on Wikipedia's popular pages 5 during a year is also used for identifying topics with most online attention. In this case the report of the 5.000 popular pages in 2016 is selected in order to analyse the first 500 popular pages. The next step is to monitor in real 
time the Trending Topics of Twitter in countries selected during a period defined. In order to do this monitoring the R-program is used with the application of extraction of the 50 Trending Topics. For the present research the code was designed for extracting the 50 Trending Topics for two moments of the day (noon and night) during one week (March 7- March 13, 2017) in 14 countries (Argentina, Belgium, Brazil, Canada, France, India, Ireland, Italy, Kenya, Mexico, Nigeria, Spain, United Kingdom, United States).

In both strategies, the selection of the topics includes all those keywords related to citizens' interests excluding all those topics related to TV shows, music, sports, religion, geography, entertainment that would be a subject matter for other research. Once the list is, obtained results are contrasted with the sustainable development goals in order to identify if there are some issues that are not covered by the institution's priorities.

\section{Results}

Results are classified in two sections those obtained through the Top down approach and those of the Bottom up approach. The first section of results is aimed to analyse which keywords of sustainable development goals have larger presence in each social media and online source selected as well as an overview of total online interactions for each keyword. This comparative analysis evidences those topics that receives most attention by citizens. On the other hand, results obtained through the bottom up approach is useful for the identification of emerging topics that are not yet covered under the sustainable development goals and could be a relevant information for developing the next strategies.

\section{Top Down Results}

Keywords with higher presence in Twitter are Climate Action and Justice, followed by the keywords with medium-high presence that are social topics such as gender equality or eradication of the hunger around the globe but also there are concerns related to the preservation of the Earth as well as natural resources (Climate Change, Clean Energy, Clean Water, 
Biodiversity) and infrastructure. On the other hand, the five keywords with lowest presence are Inclusive Societies, Ocean Sustainability, Peaceful Society, and Responsible Production. Combat Desertification and Global Partnership do not have any tweet.

Table 2.

Ranking of Keywords - Twitter

\begin{tabular}{lcc}
\hline Searchable Keywords & Search day & Engagement (replies+favorites+Rts+Total Rts) \\
\hline \#climateaction & $14 / 03 / 2017$ & 5.441 .609 \\
\#justice & $14 / 03 / 2017$ & 1.060 .001 \\
\#climatechange & $14 / 03 / 2017$ & 513.906 \\
\#genderequality & $17 / 03 / 2017$ & 431.909 \\
\#zerohunger & $16 / 03 / 2017$ & 379.785 \\
\#cleanenergy & $17 / 03 / 2017$ & 317.572 \\
\#cleanwater & $14 / 03 / 2017$ & 298.389 \\
\#biodiversity & $14 / 03 / 2017$ & 238.539 \\
\#infrastructure & $17 / 03 / 2017$ & 188.615 \\
\#wellbeing & $16 / 03 / 2017$ & 86.337 \\
\#innovation & $14 / 03 / 2017$ & 77.402 \\
\#vaw & $14 / 03 / 2017$ & 68.934 \\
\#industry & $17 / 03 / 2017$ & 17.937 \\
\#ecomicgrowth & $14 / 03 / 2017$ & 11.878 \\
\#decentwork & $14 / 03 / 2017$ & 4.565 \\
\#safecities & $14 / 03 / 2017$ & 4.058 \\
\#qualityeducation & $16 / 03 / 2017$ & 1.797 \\
\#goodhealth & $16 / 03 / 2017$ & 1101 \\
\#Sustainablecities & $14 / 03 / 2017$ & 719 \\
\#nopoverty & $16 / 03 / 2017$ & 119 \\
& &
\end{tabular}


80 Cabré-Olivé et al-Relevance of Research Goals on Social Media

\begin{tabular}{lcc}
\hline Searchable Keywords & Search day & Engagement (replies+favorites+Rts+Total Rts) \\
\hline \#inclusivecities & $14 / 03 / 2017$ & 103 \\
\#reduceinequalities & $14 / 03 / 2017$ & 75 \\
\#responsibleconsumption & $14 / 03 / 2017$ & 71 \\
\#inclusivesocieties & $14 / 03 / 2017$ & 39 \\
\#oceansustainability & $17 / 03 / 2017$ & 4 \\
\#responsibleproduction & $14 / 03 / 2017$ & 3 \\
\#peacefulsociety & $17 / 03 / 2017$ & 2 \\
\#combatdesertification & $17 / 03 / 2017$ & 0 \\
\#globalpartnership \#UN & $16 / 03 / 2017$ & 0 \\
\hline
\end{tabular}

Legend

\begin{tabular}{|l|l|}
\hline & Not Found (0) \\
High presence \\
Medium -High \\
Medium \\
Low
\end{tabular}

Note. Range on Twitter (measured by Number of Engagement (replies+favorites+Rts+Total Rts), 1-9.999 (Low) 10.000-99.999 (Medium), 100.000-999.999 (Medium-High), (+) 1.000.000 (High).

Keywords appearing in the public names of Facebook pages with more "talking about" are Industry and Justice. The latter coincides with one of the keywords with higher presence in Twitter. Innovation, Infrastructure and Good Health are keywords with a medium-high presence on Facebook pages. On the other hand, the five keywords with lowest presence are Reduce inequalities, Global Partnership for Sustainable Development, Decent Work and Inclusive Societies. The keyword Ocean Sustainability appears in two names of Facebook pages, but nobody is talking about it. 
Table 3.

Ranking of Keywords - Facebook

\begin{tabular}{|c|c|c|c|}
\hline Keywords & Search day & Total number Pages & Talking about \\
\hline Industry & $16 / 03 / 2017$ & 530 & 18.38 .422 \\
\hline Justice & $16 / 03 / 2017$ & 537 & 12.41 .246 \\
\hline Innovation & $16 / 03 / 2017$ & 491 & 878.471 \\
\hline Infrastructure & $16 / 03 / 2017$ & 469 & 513.109 \\
\hline Good Health & $16 / 03 / 2017$ & 497 & 267.324 \\
\hline Climate Change & $16 / 03 / 2017$ & 510 & 54.619 \\
\hline Well-being & $16 / 03 / 2017$ & 419 & 49.706 \\
\hline Biodiversity & $16 / 03 / 2017$ & 477 & 31.233 \\
\hline Clean Energy & $16 / 03 / 2017$ & 466 & 27.793 \\
\hline Clean Water & $16 / 03 / 2017$ & 466 & 18.030 \\
\hline Climate Action & $17 / 03 / 2017$ & 415 & 12.741 \\
\hline Violence Against Women & $17 / 03 / 2017$ & 327 & 8.856 \\
\hline Sustainable Cities & $16 / 03 / 2017$ & 105 & 8.681 \\
\hline Quality Education & $16 / 03 / 2017$ & 479 & 6.878 \\
\hline Gender Equality & $17 / 03 / 2017$ & 59 & 5.351 \\
\hline Economic Growth & $17 / 03 / 2017$ & 227 & 2.328 \\
\hline Peaceful Societies & $16 / 03 / 2017$ & 37 & 2.328 \\
\hline Safe Cities & $16 / 03 / 2017$ & 72 & 2.175 \\
\hline Combat Desertification & $16 / 03 / 2017$ & 8 & 250 \\
\hline Poverty & $16 / 03 / 2017$ & 83 & 183 \\
\hline Zero Hunger & $16 / 03 / 2017$ & 27 & 163 \\
\hline Responsible Production & $17 / 03 / 2017$ & 46 & 135 \\
\hline Responsible Consumption & $16 / 03 / 2017$ & 10 & 129 \\
\hline Inclusive Cities & $16 / 03 / 2017$ & 22 & 99 \\
\hline Inclusive Societies & $17 / 03 / 2017$ & 22 & 99 \\
\hline Decent Work & $16 / 03 / 2017$ & 56 & 83 \\
\hline $\begin{array}{l}\text { Global Partnership for } \\
\text { Sustainable Development }\end{array}$ & $16 / 03 / 2017$ & 7 & 23 \\
\hline Reduce Inequalities & $16 / 03 / 2017$ & 3 & 2 \\
\hline Ocean Sustainability & $16 / 03 / 2017$ & 2 & 0 \\
\hline
\end{tabular}


Legend

\begin{tabular}{|c|}
\hline Not Found (0) \\
\hline High presence \\
\hline Medium-High \\
\hline $\begin{array}{l}\text { Medium } \\
\text { Low }\end{array}$ \\
\hline
\end{tabular}

Note. Range on Facebook (measured by Number of Talking about (pages) 1-999 (Low), 1.000-99.999 (Medium), 100.000-999.999 (Medium-High), +1.000.000 (High).

Keywords with higher presence in Wikipedia are Quality Education (as part of the more general term Education), keywords related to preservation of the Earth (Biodiversity and Climate Change) and economy (Industry, Innovation). Those keywords with medium-high presence are social topics such as Poverty, Justice, Violence Against Women, Gender Equality and Economic Growth, on the other hand Infrastructure and keywords related to the Earth preservation (Clean Water and Combat Desertification). There are seven keywords without any presence because their definition is not included in Wikipedia (English version); these are Safe Cities, Inclusive Cities, Responsible Production, Ocean Sustainability, Inclusive Societies, Peaceful Societies and Global Partnership for Development. The five keywords with less page views are Good Health, Responsible Consumption (that redirects to the Sustainable Consumption), Decent Work, Reduce Inequalities (that redirects to Inequality) and Climate Action (that redirects to Climate Change Mitigation).

Table 4.

Ranking of Keywords - Wikipedia

\begin{tabular}{lccc}
\hline Keyword & Search date & Languages & $\begin{array}{c}\text { Page } \\
\text { views }\end{array}$ \\
\hline Quality Education (Education) & $2017-02-14-2017-03-15$ & 152 & 720.568 \\
Biodiversity & $2017-02-14-2017-03-15$ & 80 & 364.847 \\
Climate Change & $2017-02-14-2017-03-15$ & 64 & 340.059 \\
Industry & $2017-02-14-2017-03-15$ & 135 & 337.566 \\
\hline
\end{tabular}




\begin{tabular}{|c|c|c|c|}
\hline Keyword & Search date & Languages & $\begin{array}{l}\text { Page } \\
\text { views }\end{array}$ \\
\hline Innovation & $2017-02-14-2017-03-15$ & 53 & 337.566 \\
\hline Poverty & $2017-02-14-2017-03-15$ & 82 & 284.566 \\
\hline Justice & $2017-02-14-2017-03-15$ & 69 & 210.545 \\
\hline Violence Against Women & $2017-02-14-2017-03-15$ & 30 & 176.963 \\
\hline Economic Growth & $2017-02-14-2017-03-15$ & 50 & 176.142 \\
\hline Infrastructure & $2017-02-14-2017-03-15$ & 75 & 164.451 \\
\hline Gender Equality & $2017-02-14-2017-03-15$ & 43 & 162.090 \\
\hline $\begin{array}{l}\text { Clean Water (drinking water) } \\
\text { Combat Desertification } \\
\text { (desertification) }\end{array}$ & $\begin{array}{l}2017-02-14-2017-03-15 \\
2017-02-14-2017-03-15\end{array}$ & 56 & $\begin{array}{l}120.232 \\
109.884\end{array}$ \\
\hline Hunger & $2017-02-14-2017-03-15$ & 54 & 54.362 \\
\hline $\begin{array}{l}\text { Well-being } \\
\text { Clean Energy (Sustainable }\end{array}$ & $2017-02-14-2017-03-15$ & 16 & 38.339 \\
\hline $\begin{array}{l}\text { Energy) } \\
\text { Sustainable Cities (Sustainable }\end{array}$ & 2017-02-14 - 2017-03-15 & 16 & 23.140 \\
\hline $\begin{array}{l}\text { City) } \\
\text { Climate Action (Climate }\end{array}$ & $2017-02-14-2017-03-15$ & 15 & 17.202 \\
\hline Change Mitigation) & $2017-02-14-2017-03-15$ & 14 & 16.315 \\
\hline Reduce Inequalities (Inequality) & $2017-02-14-2017-03-15$ & 12 & 9.897 \\
\hline $\begin{array}{l}\text { Decent Work } \\
\text { Responsible Consumption } \\
\text { (Sustainable Consumption) }\end{array}$ & $\begin{array}{l}2017-02-14-2017-03-15 \\
2017-02-14-2017-03-15\end{array}$ & $\begin{array}{l}8 \\
8\end{array}$ & $\begin{array}{l}6.766 \\
6.095\end{array}$ \\
\hline Good Health & $2017-02-14-2017-03-15$ & 1 & 83 \\
\hline Safe Cities & $2017-02-14-2017-03-15$ & 0 & 0 \\
\hline Inclusive Cities & $2017-02-14-2017-03-15$ & 0 & 0 \\
\hline Responsible Production & 2017-02-14 - 2017-03-15 & 0 & 0 \\
\hline Ocean Sustainability & $2017-02-14-2017-03-15$ & 0 & 0 \\
\hline Inclusive Societies & 2017-02-14 - 2017-03-15 & 0 & 0 \\
\hline $\begin{array}{l}\text { Peaceful Societies } \\
\text { Global Partnership for }\end{array}$ & $2017-02-14-2017-03-15$ & 0 & 0 \\
\hline Sustainable Development & 2017-02-14 - 2017-03-15 & 0 & 0 \\
\hline
\end{tabular}

\section{Legend}

Not Found (0) 


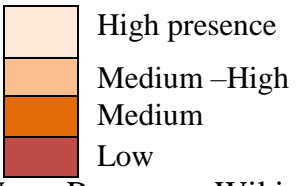

Note. Range on Wikipedia (measured by number of page views), 1-9.999 (Low), 10.000-99.999 (Medium), 100.000-299.999 (Medium-High), (+) 300.000 (High).

YouTube is the online source where all keywords are with larger or smaller presence. Keywords with more view counts are Innovation, Good Health, Violence Against Women, Clean Water and Climate Change. Keywords with medium-high presence are Industry, Poverty, Gender Equality and Infrastructure. On the other hand, the five keywords with lower presence are Justice, Peaceful Societies, Global Partnership for Sustainable Development, Reduce Inequalities and Responsible Production.

Table 5 .

Ranking of Keywords - YouTube

\begin{tabular}{lcc}
\hline Keyword & Search date & $\begin{array}{c}\text { View counts (5 videos selected with } \\
\text { more view counts) }\end{array}$ \\
\hline Innovation & $16 / 03 / 2017$ & 49.632 .612 \\
Good Health & $16 / 03 / 2017$ & 48.406 .818 \\
Violence Against Women & $16 / 03 / 2017$ & 38.622 .448 \\
Clean Water & $16 / 03 / 2017$ & 37.374 .362 \\
Climate Change & $16 / 03 / 2017$ & 30.325 .651 \\
Industry & $16 / 03 / 2017$ & 17.280 .769 \\
Poverty & $16 / 03 / 2017$ & 15.915 .425 \\
Gender Equality & $16 / 03 / 2017$ & 14.876 .578 \\
Infrastructure & $16 / 03 / 2017$ & 10.050 .049 \\
Well-being & $16 / 03 / 2017$ & 5.337 .771 \\
Biodiversity & $16 / 03 / 2017$ & 2.189 .272 \\
Climate Action & $16 / 03 / 2017$ & 1.866 .331 \\
Clean Energy & $16 / 03 / 2017$ & 1.644 .104 \\
Economic Growth & $16 / 03 / 2017$ & 1.624 .590 \\
Sustainable Cities & $16 / 03 / 2017$ & 355.845 \\
Quality Education & $16 / 03 / 2017$ & 292.029 \\
& & \\
\hline
\end{tabular}


(continued)

\begin{tabular}{lcc}
\hline Keyword & Search date & $\begin{array}{c}\text { View counts (5 videos selected with } \\
\text { more view counts) }\end{array}$ \\
\hline Safe Cities & $16 / 03 / 2017$ & 233.247 \\
Combat Desertification & $16 / 03 / 2017$ & 192.258 \\
Decent Work & $16 / 03 / 2017$ & 151.670 \\
Zero Hunger & $16 / 03 / 2017$ & 113.280 \\
Responsible Consumption & $16 / 03 / 2017$ & 67.176 \\
Inclusive Societies & $16 / 03 / 2017$ & 40.462 \\
Ocean Sustainability & $16 / 03 / 2017$ & 33.409 \\
Inclusive Cities & $16 / 03 / 2017$ & 24.414 \\
Responsible Production & $16 / 03 / 2017$ & 18.169 \\
Reduce Inequalities & $16 / 03 / 2017$ & 14.347 \\
Global Partnership for & $16 / 03 / 2017$ & 7.796 \\
Sustainable Development & $16 / 03 / 2017$ & 7.791 \\
Peaceful Societies & $16 / 03 / 2017$ & 1.543 \\
Justice & & \\
\hline
\end{tabular}

Legend

\begin{tabular}{|l|l|}
\hline & Not Found (0) \\
\hline & High presence \\
& Medium -High \\
\hline & Medium \\
\hline & Low
\end{tabular}

Note. Range on YouTube (measured by number of view counts (from 5 most viewed videos), 1-99.999 (Low), 100.000-9.999.999 (Medium), 10.000.000-29.999.999 (Medium-High), (+) 30.000.000 (High).

Lastly, a sum of total online interactions of the different social media and online resources is constructed in order to map the relevance of keywords depending on the citizens' interests. According to this ranking, the keywords with higher presence are Innovation (50.926.051), Good Health (48.675.326), Violence Against Women (38.877.201), Clean Water (37.811.013), Climate Change (37.811.013), Industry (19.474.694), Poverty (16.200.293), Gender Equality (15.475.928) and Infrastructure (10.916.224). 
86 Cabré-Olivé et al-Relevance of Research Goals on Social Media

Table 6.

Ranking of Keywords - Total online interactions

\begin{tabular}{|c|c|c|c|c|c|}
\hline Keywords & Twitter & Facebook & Wikipedia & Youtube & $\begin{array}{c}\text { Total } \\
\text { interactions }\end{array}$ \\
\hline Innovation & 77.402 & 878.471 & 337.566 & 49.632 .612 & 50.926 .051 \\
\hline Good Health & 1.101 & 267.324 & 83 & 48.406 .818 & 48.675 .326 \\
\hline $\begin{array}{l}\text { Violence Against } \\
\text { Women }\end{array}$ & 68.934 & 8.856 & 176.963 & 38.622 .448 & 38.877 .201 \\
\hline Clean Water & 298.389 & 18.030 & 120.232 & 37.374 .362 & 37.811 .013 \\
\hline Climate Change & 513.906 & 54.619 & 340.059 & 30.325 .651 & 31.234 .235 \\
\hline Industry & 17.937 & 1.838 .422 & 337.566 & 17.280 .769 & 19.474 .694 \\
\hline Poverty & 119 & 183 & 284.566 & 15.915 .425 & 16.200 .293 \\
\hline Gender Equality & 431.909 & 5.351 & 162.090 & 14.876 .578 & 15.475 .928 \\
\hline Infrastructure & 188.615 & 513.109 & 164.451 & 10.050 .049 & 10.916 .224 \\
\hline Climate Action & 5.441 .609 & 12.741 & 16.315 & 1.866 .331 & 7.336 .996 \\
\hline Well-being & 86.337 & 49.706 & 38.339 & 5.337 .771 & 5.512 .153 \\
\hline Biodiversity & 238.539 & 31.233 & 364.847 & 2.189 .272 & 2.823 .891 \\
\hline Justice & 1.060 .001 & 1.241 .246 & 210.545 & 1.543 & 2.513 .335 \\
\hline Clean Energy & 317.572 & 27.793 & 23.140 & 1.644 .104 & 2.012 .609 \\
\hline $\begin{array}{l}\text { Economic } \\
\text { Growth }\end{array}$ & 11.878 & 2.328 & 176.142 & 1.624 .590 & 1.814 .938 \\
\hline $\begin{array}{l}\text { Quality } \\
\text { Education }\end{array}$ & 1.797 & 6.878 & 720.568 & 292.029 & 1.021 .272 \\
\hline Zero Hunger & 379.785 & 163 & 54.362 & 113.280 & 547.590 \\
\hline $\begin{array}{l}\text { Sustainable } \\
\text { Cities }\end{array}$ & 719 & 8.681 & 17.202 & 355.845 & 382.447 \\
\hline $\begin{array}{l}\text { Combat } \\
\text { Desertification }\end{array}$ & 0 & 250 & 109.884 & 192.258 & 302.392 \\
\hline Safe Cities & 4.058 & 2.175 & 0 & 233.247 & 239.480 \\
\hline Decent Work & 4.565 & 83 & 6.766 & 151.670 & 163.084 \\
\hline $\begin{array}{l}\text { Responsible } \\
\text { Consumption }\end{array}$ & 71 & 129 & 6.095 & 67.176 & 73.471 \\
\hline $\begin{array}{l}\text { Inclusive } \\
\text { Societies }\end{array}$ & 39 & 99 & 0 & 40.462 & 40.600 \\
\hline $\begin{array}{l}\text { Ocean } \\
\text { Sustainability }\end{array}$ & 4 & 0 & 0 & 33.409 & 33.413 \\
\hline
\end{tabular}

(continued) 
International and Multidisciplinary Journal of Social Sciences, 6(1)

\begin{tabular}{lccccc}
\hline Keywords & Twitter & Facebook & Wikipedia & Youtube & $\begin{array}{c}\text { Total } \\
\text { interactions }\end{array}$ \\
\hline $\begin{array}{l}\text { Inclusive Cities } \\
\text { Reduce }\end{array}$ & 103 & 99 & 0 & 24.414 & 24.616 \\
$\begin{array}{l}\text { Inequalities } \\
\text { Responsible } \\
\text { Production }\end{array}$ & 75 & 2 & 9.897 & 14.347 & 24.321 \\
$\begin{array}{l}\text { Peaceful } \\
\text { Societies }\end{array}$ & 3 & 135 & 0 & 18.169 & 18.307 \\
$\begin{array}{l}\text { Global } \\
\text { Partnership for }\end{array}$ & 2 & 2.328 & 0 & 7.791 & 10.121 \\
$\begin{array}{l}\text { Sustainable } \\
\text { Development }\end{array}$ & 0 & 23 & 0 & 7.796 & 7.819 \\
\hline
\end{tabular}

\section{Legend}

\begin{tabular}{|l}
\hline Not Found $(0)$ \\
High presence \\
Medium -High \\
Medium \\
Low
\end{tabular}

Note. Range on Total interactions (measured by sum of total interactions obtained on Twitter, Facebook, Wikipedia and YouTube) 1-99.999 (Low), 100.000-999.999 (Medium), 1.000.000-9.999.999 (Medium-High), (+) 10.000.000 (High).

As result of this comparison, the relevance of Sustainable Development Goals for the citizens considering the online presence obtained is the following.

Table 7.

Relevance of Sustainable Development Goals

\begin{tabular}{ll}
\hline Sustainable Development Goal & Relevance \\
\hline No poverty & High \\
Gender Equality & High \\
Clean Water and Sanitation & High \\
Industry, Innovation, Infrastructure & High \\
Good Health and Well-being & High
\end{tabular}




\begin{tabular}{ll}
\hline Sustainable Development Goal & Relevance \\
\hline Climate Action & Medium - High \\
Peace, Justice and Strong Institutions & Medium- High \\
Quality Education & Medium-High \\
Affordable and Clean Energy & Medium-High \\
Life on Land & Medium-High \\
Decent Work and Economic Growth & Medium-High \\
Zero Hunger & Medium \\
Sustainable Cities and Communities & Medium \\
Reduced Inequalities & Low \\
Responsible Consumption and Production & Low \\
Life below Water & Low \\
Partnerships for the Goals & Low \\
\hline
\end{tabular}

\section{Bottom Up Results}

Bottom Up results are obtained through two strategies: secondary analysis of the social media reports and analysis of 50 Trending Topics of Twitter in 14 countries during one week. The topics of the secondary analysis were extracted from the yearly reports of Facebook, Twitter and Wikipedia.

\section{Topics Emerged through Secondary Analysis}

Facebook and Twitter provide ten issues as main topics of the year 2016. Among them, politics are relevant, for instance the US Presidential Election 2016 is present in the three sources analysed, Brazilian politics is a topic collected in Facebook's report and Euro2016 is from Twitter's report. Brexit is also a recurrent issue in Facebook and Twitter, it was a relevant concern by citizens from the United Kingdom, but also citizens from other countries have paid attention to this fact. Two controversial presidential candidates were topics during 2016; one of them is Rodrigo Duterte running in the Philippines' Presidential Election being a topic in Facebook, and the other one was Trump in Twitter, both candidates won the elections. Black Lives Matter also was a relevant topic during 2016 in Facebook and Twitter, this international activist movement began on Twitter under the hashtag \#BlackLivesMatter and is aimed to combat violence against black people due to a systemic racism towards them. In the case of Wikipedia, higher 
attention is paid to historical violent facts (World War I, World War II, September 11 attacks, Syrian Civil War, and Ku Klux Klan), also the list of stock market crashes and bear markets is a relevant topic in Wikipedia. Social media and other relevant online sources are themselves a relevant topic in Wikipedia, for instance Facebook, Google, YouTube and Gmail are topics included in the list of most accessed pages, as well other technological concepts such as Java (programming language). This matches with the current trend of "learn to code movement" and the aim to teach the young to program with codes since childhood. There are three more topics: one of them is Earth, representing a curiosity for knowing the place where humans are living and how it is defined; Millennials as a topic that defines a generation that are currently changing the work culture, with familiar uses of social media and technology and with more social conscientiousness; and the last one is the Zika Virus which was an important health concern during 2016.

Table 8.

Topics emerged from secondary analysis

\begin{tabular}{|c|c|c|}
\hline Facebook & Twitter & Wikipedia \\
\hline US Presidential Election & \multirow{2}{*}{ Rio2016 } & United States \\
\hline Brazilian Politics & & presidential election, 2016 \\
\hline Pokemon Go & \multirow{2}{*}{ Election2016 } & Earth \\
\hline Black Lives Matter & & Facebook \\
\hline Rodrigo Duterte \& Philippine & \multirow{2}{*}{ PokemonGo } & Java (programming \\
\hline Presidential Election & & language) \\
\hline Olympics & \multirow{2}{*}{ Euro2016 } & Google \\
\hline Brexit & & YouTube \\
\hline Super Bowl & \multirow{2}{*}{ Oscars } & World War II \\
\hline David Bowie & & World War I \\
\hline \multirow[t]{8}{*}{ Muhammad Ali } & \multirow{3}{*}{ Brexit } & Millennials \\
\hline & & Wikipedia \\
\hline & & Zika virus \\
\hline & $\begin{array}{l}\text { BlackLivesMatter } \\
\text { Trump }\end{array}$ & List of stock market crashes \\
\hline & RIP & $\begin{array}{l}\text { and bear markets } \\
\text { September } 11 \text { attacks }\end{array}$ \\
\hline & GameOfThrones & Gmail \\
\hline & & Syrian Civil War \\
\hline & & Ku Klux Klan \\
\hline
\end{tabular}




\section{Topics emerged from the Monitoring of Trending Topics in Twitter}

Topics emerged from the analysis of Trending Topics in Twitter are diverse, but there is a high presence of women's movement probably because the week chosen included March 8, the International Day of Women. However, at the same time, there are other topics that are present in these Trending Topics, such as the Violence Against Women, Frauds, or civil movements are present in these topics. Results are introduced in two steps: first, an overview of topics selected by each country and, second a table comparing the topics selected and if they are or not among the Sustainable Development Goals in order to find out if some topics are not yet taken into account by the United Nations.

Table 9.

Topics emerged from Monitoring TT in Twitter (14 countries)

\begin{tabular}{lcl}
\hline Country & $\begin{array}{c}\text { Number of } \\
\text { TT selected }\end{array}$ & Trending Topics (TT) \\
\hline Argentina & & \#MarchaCGT \#Movil \#TrenBelgranoNorte \\
& 15 & \#ParoDocenteNacional \#TránsitoBUE \\
& \#DiaInternacionalDeLaMujer \#DíaMundialDelRiñón \\
& \#Legislatura \#NiUnaMenos \#pobreza \\
& \#AprenderEnEquidad \#CambiandoJuntas \#maspobres \\
& \#CrisisPetrolera \#Transporte \\
& & \#cities4Europe \#womensday \#privacy \#openbelgium \\
& \#opendata \\
& \#refugees \#CircularEconomy \#WikiLeaks \\
& \#cleanenergyeu \#JourneeDesDroitsDesFemmes \\
& \#genderequality \#SolarPowerSummit \#ManifesteDes350 \\
& \#smartcitybru \#SDGGender \#BokoHaram \#Invest4Future \\
& & \#equality \#CleanEnergyEU \#LEmissionPolitique \\
& & \#villapolitica \#FutureofEurope \#bitcoin \#Kennedytunnel \\
& & \#Transatlantic2017 \#fukushima \#pulseofeurope \\
\hline & & Justiça Federal \#ViasExpressas Wikileaks \#DiaDaMulher \\
& \#NiUnaMenos \#\#Via Campesina
\end{tabular}

(continued) 


\begin{tabular}{|c|c|c|}
\hline Country & $\begin{array}{l}\text { Number of } \\
\text { TT selected }\end{array}$ & Trending Topics (TT) \\
\hline Canada & 20 & $\begin{array}{l}\text { \#InternationalWomensDay \#MuslimBan Wikileaks } \\
\text { \#Budget2017 \#LeadershipYQL Criminal Code \#IWD17 } \\
\text { \#StartupWomen \#EqualityMatters \#nlschools } \\
\text { \#ÉgalitéCompte } \\
\text { \#NewMedicationSideEffects \#united4cymh (mental health) } \\
\text { \#NoFrauds \#changetogether \#NativeNationsRise } \\
\text { \#ElectionResults } \\
\text { \#EqualityBreakfast \#DevelopersDen \#Fukushima }\end{array}$ \\
\hline France & 13 & $\begin{array}{l}\text { \#LibéDesRéfugiés \#techcare2017 } \\
\text { \#JourneeDesDroitsDesFemmes } \\
\text { \#InternationalWomensDay \#ellesmarchent } \\
\text { \#journeemondialedelafemme \#LEmissionPolitique } \\
\text { \#NoFrauds } \\
\text { \#JusticePourSofiane \#Fukushima \#NousAccusons } \\
\text { \#ResponsabilitéCivile \#opensource }\end{array}$ \\
\hline India & 14 & $\begin{array}{l}\text { National Highways \#NoConditionsApply (gender equality) } \\
\text { \#womensday2017 \#WikiLeaks \#solarpower \#BeingAWoman } \\
\text { \#RespectWomenLikeSRK \#GoogleNext17 \#UnitedByHalf } \\
\text { \#pulwamaencounter (terrorism) \#Parliament } \\
\text { \#InnovationHasAName \#ElectionResults \#SupremeCourt }\end{array}$ \\
\hline Ireland & 23 & $\begin{array}{l}\text { \#Strike4Repeal \#InternationalWomensDay } \\
\text { \#innovation \#CITInnov8 \#engineersweek \#Budget2017 } \\
\text { \#localenterprise \#GoggleboxIRL \#March4Repeal \#faircity } \\
\text { \#BeBoldForChange \#solidarity \#ISIS \#GlobalGreening } \\
\text { \#Right2Water \#foodwaste National Maternity Hospital } \\
\text { \#NoFrauds \#RailsGirlsDUB \#GAAHealth \#FutureIsGreen } \\
\text { \#UCCFoodmatters \#AutismAndMe }\end{array}$ \\
\hline Italy & 14 & $\begin{array}{l}\text { \#giornatadelladonna \#scioperodelledonne \#IWD2017 } \\
\text { \#Wikileaks } \\
\text { \#InternationalWomensDay \#MetticiEnergia } \\
\text { \#FestaDellaDonna } \\
\text { \#womensday \#povertà \#lavoroautonomo \#Governo5Stelle } \\
\text { \#Fukushima \#MafiaCapitale \#comunicazione }\end{array}$ \\
\hline
\end{tabular}




\section{Cabré-Olivé et al-Relevance of Research Goals on Social Media}

\begin{tabular}{|c|c|c|}
\hline Country & $\begin{array}{l}\text { Number of } \\
\text { TT selected }\end{array}$ & Trending Topics (TT) \\
\hline Kenya & 26 & $\begin{array}{l}\text { \#DevCon2017 \#HealthyNation \#BeBoldForChange } \\
\text { \#LecturersStrike \#WeAreAllKenyans (solidarity) } \\
\text { \#CleanEnergyKe } \\
\text { \#IWD2017 \#InternationalWomensDay \#HealthStrikeDay94 } \\
\text { Kenyatta National Hospital \#OperationSaveNyamai } \\
\text { \#SGRTransformingTransport \#Equality } \\
\text { \#StrengtheningResponse } \\
\text { \#AdaptCleanEnergy \#Kenyans4Peace No Frauds } \\
\text { \#Kenyapreneurship \#VoteNowKenyaDecides } \\
\text { \#KaribuMtongwe } \\
\text { \#United4Kiambu \#ShameOnKEMedia \#HowNationsProsper } \\
\text { \#AfricaLD \#LegalAbuse \#AfricaIndustry }\end{array}$ \\
\hline Mexico & 5 & $\begin{array}{l}\text { \#DiaInternacionalDeLaMujer \#Wikileaks } \\
\text { \#DíaMundialDelRiñón \#ViviendaPorMéxico } \\
\text { \#EquidadEnPuebla }\end{array}$ \\
\hline Nigeria & 9 & $\begin{array}{l}\text { \#WomensDay \#BeBoldForChange \#PeerFundingPays } \\
\text { \#InternationalWomensDay \#BreakFreeWoman \#GirlsCount } \\
\text { \#PeerFundYourProject \#EdoWomen4Agric } \\
\text { StudyWorkAbroadABJ }\end{array}$ \\
\hline Spain & 21 & $\begin{array}{l}\text { \#cierraUNICEF \#LaPAHsePlanta \#CientíficasPrecarias } \\
\text { \#IniciativaPymes \#ConCienciaEscuela } \\
\text { \#DiaInternacionalDeLaMujer \#CorrupciónARV } \\
\text { \#InternationalWomensDay \#patera \#HuelgaGeneralEducativa } \\
\text { \#LaUniSeRebela \#DíaMundialdelRiñón \#NiUnRoboMás } \\
\text { \#STOPCorrupció \#ProtocoloContaminación } \\
\text { \#DíaDaClaseObreiraGalega \#NoOlvidamos \#Fukushima } \\
\text { \#biología \#Sentencia9nARV \#HuelgaNoEsDelito }\end{array}$ \\
\hline $\begin{array}{l}\text { United } \\
\text { Kingdom }\end{array}$ & 16 & $\begin{array}{l}\text { \#tech4goodawards \#digitransform17 \#RewritingTheCode } \\
\text { \#InternationalWomenDay \#Budget2017 \#Strike4Repeal } \\
\text { \#GoogleNext17 \#WIREDHealth \#digitalgaggle } \\
\text { \#selfemployed \#ReportItToStopIt \#dyingfrominequality } \\
\text { \#NewEconomics \#futureofwork \#bloodcancerconf \#brexitbill }\end{array}$ \\
\hline $\begin{array}{l}\text { United } \\
\text { States }\end{array}$ & 14 & $\begin{array}{l}\text { \#womenASCOA \#Trumpcare \#ParoDeMujeresPR } \\
\text { \#Budget2017 \#InternationalWomensDay \#GoogleNext17 No } \\
\text { Frauds \#NativeNationsRise How Healthy Are You } \\
\text { \#ElectionResults \#peoplepower \#iwdtoronto } \\
\text { \#CancerMoonshot \#PlanFiscalPR }\end{array}$ \\
\hline
\end{tabular}


Once the list of Trending Topics monitored is obtained, the second step is to compare if they are present or not among the Sustainable Development Goals defined. Therefore, a classification of Trending Topics (TT, hereinafter) is developed in order to compare if all topics are covered or not under the Sustainable Development Goals. In this classification, we distinguish between those topics that are included among the 17 SDG and those that are not.

Three TT are directly related to the goal of No Poverty, for instance the hashtag \#pobreza. There are 34 TT collected that are related to the goal of Gender Equality. Most of them focused on the dissemination of the International Day of Women and Equality (ex: \#IWD17, \#JourneeDesDroitsDesFemmes, \#genderequality, among others), others focused on the Sexual Reproductive Rights of Women (ex: \#March4Repeal) and Violence Against Women (ex: \#ReportItToStopIt). Clean Water and Sanitation has only 1 TT that is \#Right2Water. Industry, Innovation, Infrastructure is another SDG that contains many TT, specifically 24, with hashtags such as \#innovation for the keyword innovation; TT related to infrastructure and transport (ex: \#Viasexpressas, \#Transporte) are the most used. Good Health and Well-being have 7 TT of health in a global perspective and mental health particularly (ex: \#united4cymh). Climate action has one TT that it is \#NousAccusons. There are 28 TT identified related to the goal of Justice, Peace and Strong Institutions. Terrorism is one of them (ex: \#BokoHaram \#ISIS), others are against fraud (ex: \#NoFrauds, \#STOPCorrupció), related to political elections (ex: \#VoteNowKenyaDecides), justice (ex: Justiça Federal, \#SupremeCourt) and peace (ex: \#Kenyans4peace). There are 7 TT related to Quality Education, most of them with mobilizations to claim rights in education focused also on teachers' rights (ex: \#Parodocentenacional, \#Lecturestrike). There are $10 \mathrm{TT}$ related to the SDG Affordable and Clean Energy focused on clean energy mostly (ex. \#cleanenergyEU) and specific energy (ex: \#solarpower). Only one TT identified is related to Life of Land, that is \#biología. There are 15 TT identified related to the goal Decent Work and Economic Growth with topics focused on autonomous jobs (ex: \#lavoroautonomo, \#IniciativaPymes, \#selfemployed), workers' rights (ex: \#MarchaCGT), and investment for future work (ex. \#futureofwork), TT related to the general economy and 


\section{Cabré-Olivé et al-Relevance of Research Goals on Social Media}

budgets are present (ex: \#Transatlantic2017, \#budget2017). There are two TT related to Zero Hunger and they focus on food and waste (ex: \#UCCFoodmatters, \#foodwaste). There are six TT related to Sustainable Cities and Communities that are focused on smart cities and innovation, fair cities (ex: \#smartcitybru, \#CITInnov8) as well as the Housing right claim (ex: \#ViviendaPorMéxico, \#LaPAHsePlanta). There are 7 TT related to Reduced Inequalities (ex: \#equality, \#equidadenpuebla, \#egalitécompte). Lastly, no Trending Topics were identified that relate to the following three SDG: Responsible Consumption and Production, Life below Water, Partnerships for the Goals.

The Trending Topics identified that are not included in the Sustainable Development Goals are the following: topics related to Open Data (ex: \#opendata, \#openbelgium, \#opensource) and debates focused on privacy and transparency of information (ex: \#privacy \#wikileaks). Also, debates around opening codes or learninh how to code are present among citizens (ex. \#Rewritingthecode, RailsgirlsDUB). There is concern about racism (ex: \#muslimban, \#JusticePourSofiane) and about the most vulnerable people living in bad conditions, for instance refugees (ex: \#refugees \#patera), the recognition of minorities' rights (ex: \#viacampensina, \#NativeNationsRise) and solidarity itself (ex: \#solidarity). Another trending topic is health, particularly striking are topics such as cancer (ex: \#bloodcanferconf, \#cancernoonshot) and kidneys, but also issues related to the health system (ex: \#HealthStrikeDay94, \#Trumpcare). Concerning the economy there are trending topics with new contributions such as bitcoin or circular economy, but also peer-to-peer investment for implementing new initiatives (ex. \#PeerFundingPays, \#PeerFundYourProject). There are worries related to disasters, as for instance, the consequences of Fukushima, as well as the scandal for not having a team to save Nyamai, or disagreeing with the information disseminated by Media (ex. \#ShameonKmedia). Lastly, it is important to highlight that there are two trending topics defending the need of maintaining Europe united and its benefits (ex. \#FutureofEurope, \#pulseofeurope). Last but not least, there are concerns related to the consequences of breaking apart from Europe such as Brexit, with the Trending Topic of \#brexitbill. And the last trending topic collected, which is 
not present in the SDG, is the civil movement against Trump's policies that impair the civil rights acquired (ex: \#peoplepower).

Table 10.

Comparative analysis of the topics emerged with Sustainable Development Goals

\begin{tabular}{|c|c|c|}
\hline $\begin{array}{l}\text { Sustainable } \\
\text { Development } \\
\text { Goal }\end{array}$ & Topics included in the Goal & Topics not included in 17 SDG \\
\hline No poverty & \#pobreza \#maspobres \#povertà & \multirow[b]{2}{*}{$\begin{array}{l}\text { \#privacy \#openbelgium \#opendata } \\
\text { \#refugees } \\
\text { \#WikiLeaks } \\
\text { \#fukushima } \\
\text { \#Via Campesina } \\
\text { \#MuslimBan } \\
\text { \#NativeNationsRise } \\
\text { \#LibéDesRéfugiés } \\
\text { \#opensource } \\
\text { \#solidarity } \\
\text { RailsGirlsDUB } \\
\text { \#OperationSaveNyamai } \\
\text { \#ShameOnKEMedia } \\
\text { \#patera } \\
\text { \#RewritingTheCode } \\
\text { \#bloodcancerconf } \\
\text { \#CancerMoonshot } \\
\text { \#DíaMundialDelRinón } \\
\text { \#Trumpcare } \\
\text { \#HealthStrikeDay94 } \\
\text { \#JusticePourSofiane } \\
\text { \#FutureofEurope } \\
\text { \#pulseofeurope } \\
\text { \#brexitbill } \\
\text { \#peoplepower } \\
\text { \#CircularEconomy } \\
\text { \#bitcoin } \\
\text { \#PeerFundingPays } \\
\text { \#PeerFundYourProject }\end{array}$} \\
\hline Gender Equality & $\begin{array}{l}\text { \#DiaInternacionalDeLaMujer } \\
\text { \#NiUnaMenos } \\
\text { \#AprenderEnEquidad } \\
\text { \#CambiandoJuntas } \\
\text { \#womensday } \\
\text { \#JourneeDesDroitsDesFemmes } \\
\text { \#genderequality } \\
\text { \#ManifesteDes350 } \\
\text { \#SDGGender } \\
\text { \#DiaDaMulher } \\
\text { \#InternationalWomensDay } \\
\text { \#IWD17 \#StartupWomen } \\
\text { \#ellesmarchent } \\
\text { \#journeemondialedelafemme } \\
\text { \#NoConditionsApply } \\
\text { \#womensday2017 } \\
\text { \#BeingAWoman } \\
\text { \#RespectWomenLikeSRK } \\
\text { \#UnitedByHalf } \\
\text { Strike4Repeal } \\
\text { \#March4Repeal } \\
\text { \#BeBoldForChange } \\
\text { \#giornatadelladonna } \\
\text { \#scioperodelledonne } \\
\text { \#FestaDellaDonna } \\
\text { \#BreakFreeWoman \#GirlsCount } \\
\text { \#EdoWomen4Agric } \\
\text { \#CientíficasPrecarias } \\
\text { \#ReportItToStopIt } \\
\text { \#womenASCOA }\end{array}$ & \\
\hline
\end{tabular}




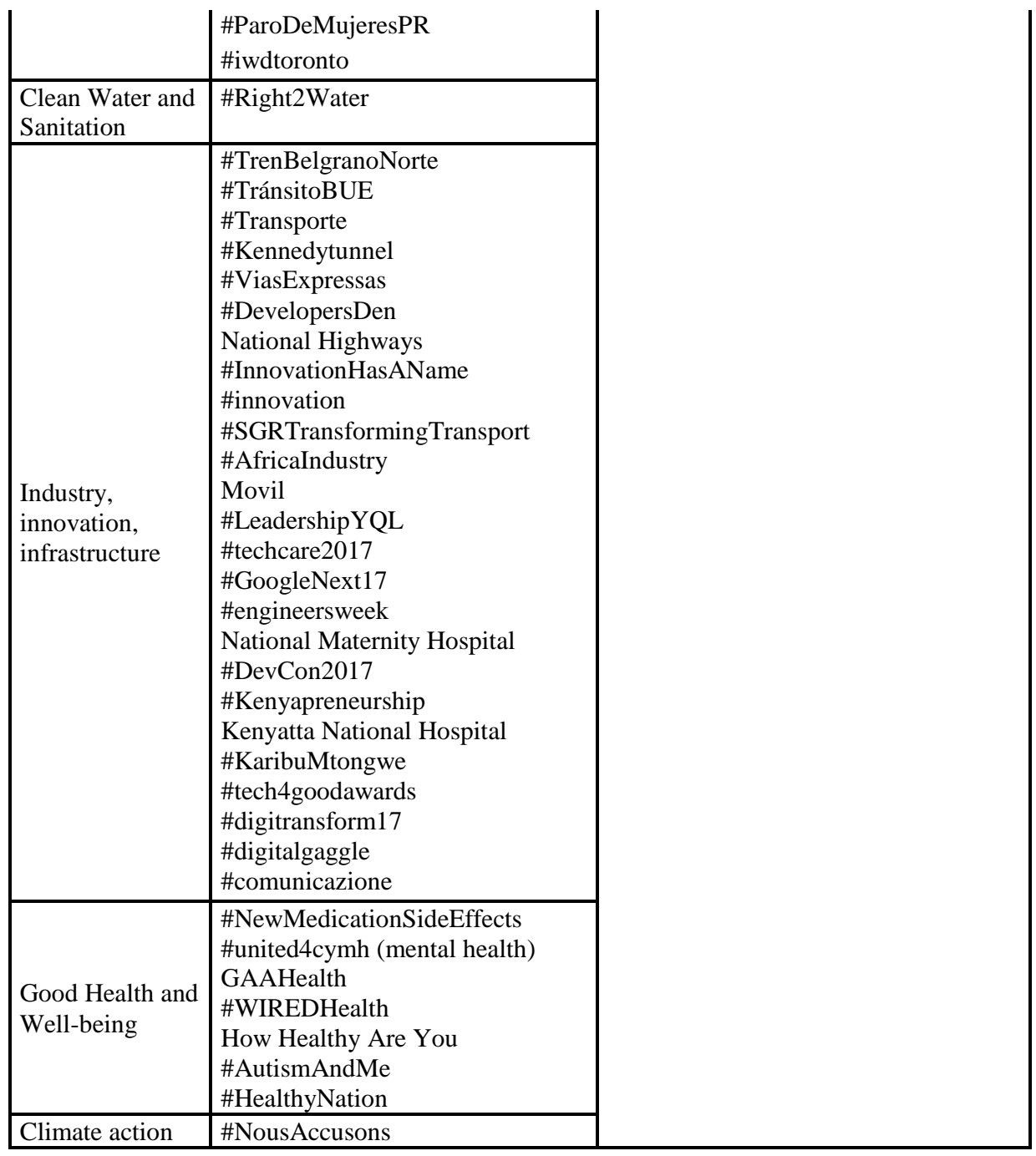


Peace, Justice and strong institutions
\#Legislatura

\#LEmissionPolitique

\#villapolitica

Justiça Federal

\#NoFrauds

\#Parliament

\#ElectionResults

\#SupremeCourt

\#Kenyans4Peace

\#LegalAbuse

\#CorrupciónARV

\#NiUnRoboMás

\#STOPCorrupció

\#pulwamaencounter (terrorism)

\#BokoHaram

\#ISIS

\#NoOlvidamos

MafiaCapitale

Criminal Code

\#WeAreAllKenyans

\#StrengtheningResponse

\#VoteNowKenyaDecides

\#ElectionResults

\#ResponsabilitéCivile

\#Governo5Stelle

\#HuelgaNoEsDelito

\#cierraUNICEF

\#Sentencia9nARV \#nlschools

StudyWorkAbroadABJ

\#ConCienciaEscuela

\#ParoDocenteNacional

\#LecturersStrike

\#HuelgaGeneralEducativa

\#LaUniSeRebela

\#cleanenergyeu

\#SolarPowerSummit

Affordable and

Clean Energy
\#CleanEnergyEU

\#solarpower

GlobalGreening

\#FutureIsGreen 


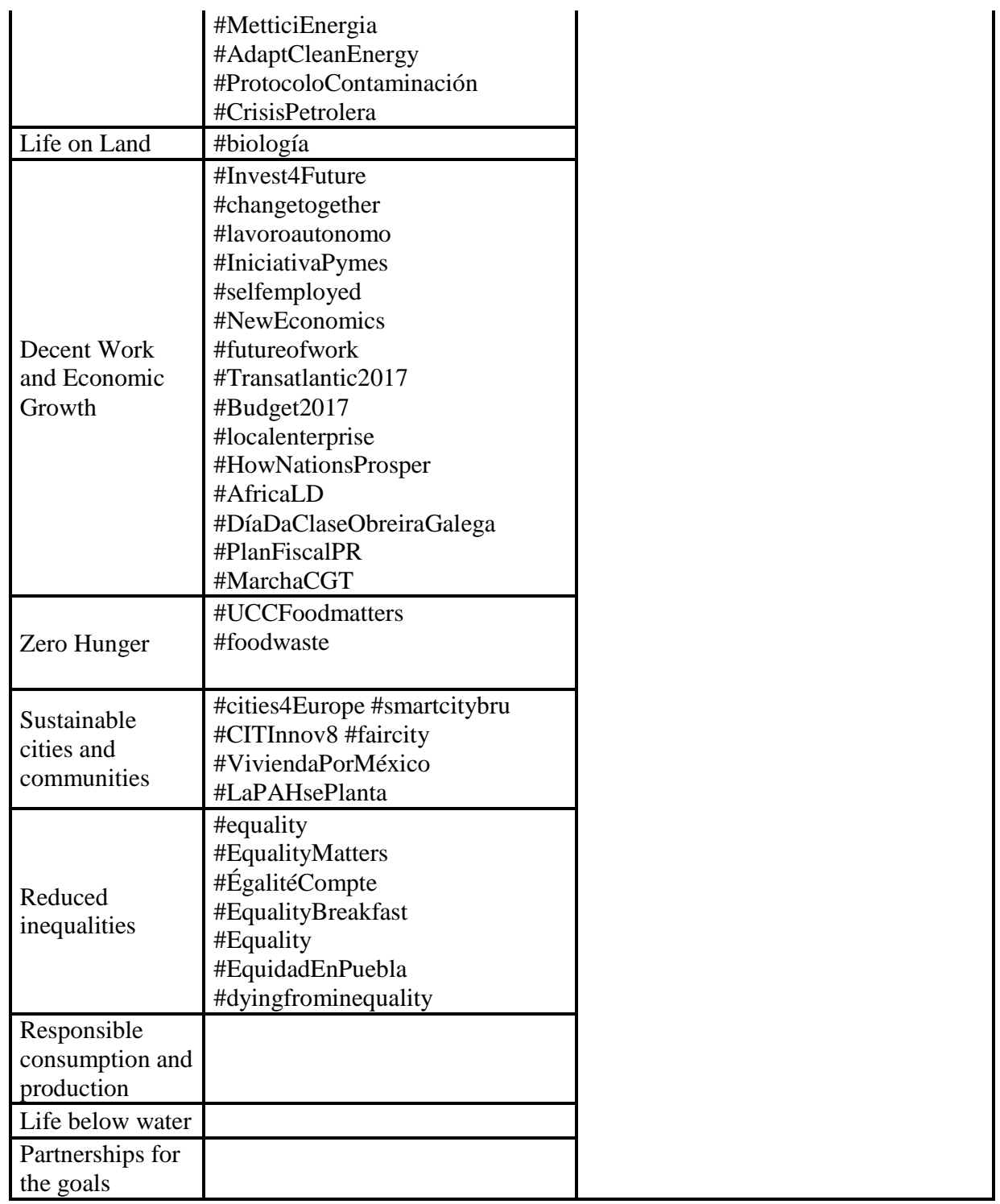




\section{Discussion}

This methodology introduces a new methodology to identify the relevance of the research goals that are defined by institutions or research teams. Until now, the consultations about issues of relevance and social impact were only addressed to an expert community on those topics. But now, with data available in social media we can analyse the voices of other social agents and citizens regarding these goals defined. The methodology serves to identify which goals are more relevant for the users of social media and if there are, some topics that are not covered by the research goals defined. This strategy is useful for being more connected to the needs and concerns of citizens and can help to refine the research goals according to this information collected.

\section{Notes}

${ }^{1}$ Sustainable Development Goals (UN):

http://www.un.org/sustainabledevelopment/sustainable-development-goals/ Accessed March 10,2017

${ }^{2}$ Statista: Statistics and facts about social media usage:

https://www.statista.com/topics/1164/social-networks/ Accessed March 10, 2017

${ }^{3}$ Facebook's 2016 Year in Review: http://newsroom.fb.com/news/2016/12/facebook-2016year-in-review/ Accessed March 10, 2017

${ }^{4}$ Twitter Reveals Top Trending Topics and Retweets of 2016: Rio Olympics, Pokemon Go and More!: http://www.usmagazine.com/entertainment/news/twitter-reveals-top-trendingtopics-retweets-of-2016-w454091 Accessed March 10, 2017

52016 Popular Pages - Wikipedia:

https://en.wikipedia.org/wiki/User:West.andrew.g/2016_Popular_pages Accessed March 10, 2017

\section{References}

Altmann, E.G., Whichard, Z.L., \& Motter, A.E. (2013). Identifying Trends in Word Frequency Dynamics. Journal of Statistical Physics, 151(1-2), 277-288. doi: 10.1007/s10955-013-0699-7

Aubert, A., \& Soler, M. (2006). Dialogism: The dialogic turn in the social sciences. In J.L. Kincheloe \& R.A. Horn (Eds.), The Praeger handbook of education and psychology, Vol. 3 (pp. 521-529). London: Praeger Publishers 
Bastos, M.T., Raimundo, R.L.G., \& Travitzki, R. (2013). Gatekeeping Twitter: message diffusion in political hashtags. Media, Culture, \& Society, 35(2), 260-270. doi: 10.1177/0163443712467594

Broersma, M., \& Graham, T. (2013). Twitter as a news source: How Dutch and British newspapers used tweets in their news coverage, 20072011. Journalism Practice, 7(4), 446-464. doi: 10.1080/17512786.2013.802481

Bruns, A., \& Liang, Y.E. (2012). Tools and methods for capturing Twitter data during natural disasters. First Monday, 17(4). doi: 10.5210/fm.v17i4.3937

Camarinha-Matos, L.M., \& Afsarmanesh, H. (2004). A roadmapping methodoloy for strategic research on VO. In L.M. Camarinha-Matos \& H. Afsarmanesh (Eds.), Collaborative networked organizations - A research agenda for emerging business models. London: Springer.

Cayuela, M.L., van Zwieten, L., Singh, B.P., Jeffery, S., Roig, A., \& Sánchez-Monedero, M.A. (2014). Biochar's role in mitigating soil nitrous oxide emissions: A review and meta-analysis. Agriculture, Ecosystems \& Environment, 191, 5-16. doi: 10.1016/j.agee.2013.10.009

Flecha, R., Soler-Gallart, M., \& Sorde, T. (2015). Social impact: Europe must fund social sciences. Nature, 528(7581), 193. Retrieved from $10.1038 / 528193 \mathrm{~d}$

Gómez, A. (2014). New developments in mixed methods with vulnerable groups. Journal of Mixed Methods Research, 8(3), 317-320. doi: $10.1177 / 1558689814527879$

Grasso, V., \& Crisci, A. (2016). Codified Hashtags for Weather Warning on Twitter: an Italian Case Study. Plos Currents, Rapid, 1-16. doi: 10.1371/currents.dis.967e71514ecb92402eca3bdc9b789529

Khang, H., Ki, E.-J., \& Ye, L. (2012). Social Media Research in Advertising, Communication, Marketing, and Public Relations, 1997-2010. Journalism \& Mass Communication Quarterly, 89(2), 279-298. doi: $10.1177 / 1077699012439853$

Miyairi, N. (2014). Open science and scientific data. Journal of Information Processing and Management, 57(2), 80-89. doi: 10.1241/johokanri.57.80 
Molloy, J.C. (2011). The open knowledge foundation: Open data means better science. PLoS Biology, 9(12), e1001195. doi: 10.1371/journal.pbio.1001195

Nam, Y., Lee, Y.O., \& Park, H.W. (2014). Measuring web ecology by Facebook, Twitter, blogs and online news: 2012 general election in South Korea. Quality \& Quantity, 49(2), 675-689. doi: 10.1007/s11135-014-0016-9

Ngai, E.W.T., Tao, S.S.C., \& Moon, K.K.L. (2015). Social media research: Theories, constructs, and conceptual frameworks. International Journal of Information Management, 35(1), 33-44. doi: 10.1016/j.ijinfomgt.2014.09.004

Redondo, G. (2016). Dialogic Leadership and New Alternative Masculinities: Emerging Synergies for Social Transformation. Masculinities \& Social Change, 5(1), 70-91. doi: 10.17583/mcs.2016.1929

Schulz, M.S. (2016). Debating futures: Global trends, alternative visions, and public discourse. International Sociology, 31(1), 3-20. doi: $10.1177 / 0268580915612941$

Small, T.A. (2011). What the Hashtag? Information, Communication \& Society, 14(6), 872-895. doi: 10.1080/1369118X.2011.554572

Torres-Nabel, L.C. (2015). Redes Sociales y Marcos Cognitivos. El Caso \#YaMeCansé y el Conflicto de Ayotzinapa en México, 2014. International and Multidisciplinary Journal of Social Sciences, 4(2), 175-193. doi: 10.17583/rimcis.2015.1570

Valkila, N., \& Saari, A. (2013). Experts' view on Finland's energy policy. Renewable and Sustainable Energy Reviews, 17, 283-290. doi: 10.1016/j.rser.2012.09.036

Valls, R., Puigvert, L., Melgar, P., \& Garcia-Yeste, C. (2016). Breaking the Silence at Spanish Universities: Findings From the First Study of Violence Against Women on Campuses in Spain. Violence Against Women, 22(13), 1519-1539. doi: 10.1177/1077801215627511

Wandhöfer, T., Taylor, S., Walland, P., Geana, R., Weichselbaum, R., Fernandez, M., \& Sizov, S. (2012). Determining citizens' opinions about stories in the news media: analysing Google, Facebook and Twitter. eJournal of eDemocracy \& Open Government (JeDEM), 4(2), 198-221. 
Whyte, A., \& Pryor, G. (2011). Open Science in Practice: Researcher Perspectives and Participation. International Journal of Digital Curation, 6(1), 199-213. doi: 10.2218/ijdc.v6i1.182

Woelfle, M., Olliaro, P., \& Todd, M.H. (2011). Open science is a research accelerator. Nature Chemistry, 3(10), 745-748. doi: 10.1038/nchem.1149

Wu, J., Sun, H., \& Tan, Y. (2013). Social media research: A review. Journal of Systems Science and Systems Engineering, 22(3), 257-282. doi: 10.1007/s11518-013-5225-6

Joan Cabré-Olivé is Postdoctoral Researcher at the Department of Pedagogy, University Rovira i Virgili, Spain

Ramon Flecha-García is professor at the Department of Sociology, University of Barcelona, Spain

Vladia Ionescu is PhD student at the Department of Pedagogy, University Rovira i Virgili, Spain

Cristina Pulido is associate professor at the Departament of Sociology, University of Barcelona, Spain

Teresa Sordé-Martí is professor at the Departament of Sociology, Autonomous University of Barcelona, Spain

Contact address: Department de Pedagogia, Facultat de Ciències de l'Educació, Universitat Rovira i Virgili, Campus Sescelades, Ctra. de Valls, s/n -43007- Tarragona. Email: joan.cabre@urv.cat 


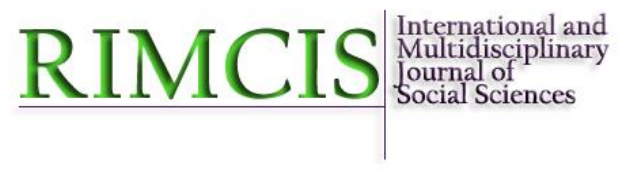

\section{Hipatia Press}

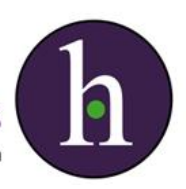

Instructions for authors, subscriptions and further details:

http://rimcis.hipatiapress.com

\section{Alternatives to Capitalism. Proposals for a Democratic Economy}

Alfonso Rodríguez ${ }^{1}$

1) University of Barcelona, Spain

Date of publication: March $30^{\text {th }}, 2017$

Edition period: March 2017 - July 2017

To cite this article: Rodríguez, A. (2017). Alternatives to Capitalism.

Proposals for a Democratic Economy [Review of the book]. International and Multidisciplinary Journal of Social Sciences, 6(1), 103-105. doi :

10.17583/rimcis.2017.2651

To link this article: http://doi.org/10.17583/rimcis.2017.2651

\section{PLEASE SCROLL DOWN FOR ARTICLE}

The terms and conditions of use are related to the Open Journal System and to Creative Commons Attribution License (CC-BY). 
RIMCIS - International and Multidisciplinary Journal of Social

Sciences Vol. 6 No.1 March 2017 pp. 103-105

\section{Review}

Hahnel, R, \& Wright, E.O. (2016). Alternatives to Capitalism. Proposals for a Democratic Economy. London and New York: Verso. ISBN 9781784785048

Both authors of this book have a long history of work on alternatives to capitalism from a perspective of economic democracy and social just. Robin Hahnel, together with Michael Albert, has worked for more than two decades in the design of an anti-capitalist economic model named "participatory economic", first proposed in their 1991 book The Political Economy of Participatory Economics (Princeton University Press) and more recently outlined in Hahnel's Of the People, By the People: The Case for a Participatory Economy (AK Press, 2012). Erik Olin Wright started the Real Utopias Project in 1990, for identifying and analyzing a series of institutional and organizational configurations that embody emancipatory ideals and are at the same time viable and sustainable, and in 2010 published the book Envisioning Real Utopias (Verso), one of his most important publications in this matter. Alternatives to Capitalism: Proposals for a Democratic Economy, more than a reading intended to deepen in these two perspectives of social transformation, contains a friendly but nevertheless critical debate of the authors on each other's proposals.

Divided into two rounds of discussions, the book begins with an exposition by Robin Hahnel of the main features and institutions proposed 


\section{Rodríguez - Alternatives to Capitalism [Book Review]}

for a model of a participatory economy (self-governing democratic councils of workers and consumers, jobs balances for empowerment and desirability, compensation according to effort, and participatory planning). The annual participatory planning procedure, which suggests the possibility to eradicate the use of market-like processes in the production and allocation of every product and service, is given special attention in this section, for it is the core feature of the model. In the base of these arguments Erik Olin Wright, after highlighting points of agreement, questions the functioning of such a model in terms of household consumption, public goods planning, externalities, risk taking innovation and the organization of work and pay, and is later given answer to his critiques by Hahnel in the final section of this half of the book.

Presenting a contrasting proposal for not being a detailed economic model but an open-ended analysis of general principles and values for organizational configurations and institutional transformations that foster the social empowerment, in the second round of discussion Wright introduces the framework of his proposal for envisioning the pathway to overcome capitalism and, which lies on the ideal of real utopias and a new conception of socialism. Robin Hahnel then elaborates a critique of the proposal, having among its main arguments a defense of the idea that markets, a main feature of today's capitalist economic system, should be substituted by some other kind of mechanism of allocation of resources, such as a participatory planning procedure. An answer is given by Wright, both in defense of his own original proposal (which leaves room for markets in a non-capitalist economy) and in response of some of Hahnel's main ideas behind the participatory economics.

The reader of this book may find of great value not only the practical and theoretical contributions of both frameworks (the participatory economics and the real utopias approach) to the analysis of strategies and scenarios of social transformation beyond capitalism, but also the deep analysis that both authors make on each other's proposals and the arguments (in favor and against) that they present for the realization of their utopian ideals. Debates such as the one around the role of markets in a post-capitalist society, in which the final decision is not determined but instead left to the reader's 
choice, are an example of the kind of analysis that can be enjoyed in this very recommendable book.

Alfonso Rodríguez, University of Barcelona alfonso.r.o88@gmail.com 


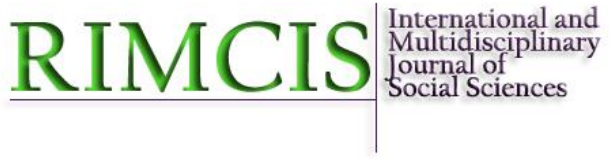

Hipatia Press

www.hipatiapress.com

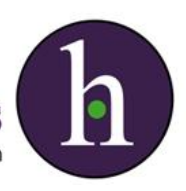

Instructions for authors, subscriptions and further details:

http://rimcis.hipatiapress.com

\section{List of Reviewers}

Date of publication: March $30^{\text {th }}, 2017$

Edition period: March 2017 - July 2017

To cite this article: (2017). List of Reviewers. International and Multidisciplinary Journal of Social Sciences, 6(1), 106. doi: 10.17583/rimcis.2017.2647

To link this article: http://doi.org/10.17583/rimcis.2017.2647

\section{PLEASE SCROLL DOWN FOR ARTICLE}

The terms and conditions of use are related to the Open Journal System and to Creative Commons Attribution License (CC-BY). 


\section{List of Reviewers}

We would really like to thank to 2016 Reviewers. Their effort and contributions have increased the quality and scientificity of the journal. The International and Multidisciplinary Journal of Social Sciences owes this to those who have been peer reviewers during this time. Yours sincerely,

Olga Serradell

Editor

Aiello, Emilia

Alonso, Eva

Morlà, Teresa

Alvarez, Gemma

Alvarez Cifuentes, Pilar

Newell, Robert

Burgués de Freitas, Ana

Ojo, Matthias

Buslón, Nataly

Peña Axt, Juan

Cabre, Joan

Poncian, Japhace

Castro, Marcos

Ramis, María del Mar

De Botton, Lena

Redondo, Gisela

Duque, Elena

Ríos, Oriol

Girbes, Sandra

Roblizo, Manuel

García, Rocio

Rodríguez, Alfonso

García Yeste, Carme

Sánchez, María Carmen

Joanpere, Mar

Macías, Fernando

Schubert, Tinka

Melgar, Patricia

Serrano, Maria Angeles

Merodio, Guiomar

Sordé, Teresa

Molina, Silvia

Taberner, José

Torres Nabel, Luis

Villarreal, Jorge 